\title{
Reviewing the class of Al-rich Ti-Al alloys: modeling high temperature plastic anisotropy and asymmetry
}

\author{
Helal Chowdhury ${ }^{*}$, Holm Altenbach², Manja Krüger ${ }^{3,4}$ and Konstantin Naumenko²
}

\begin{abstract}
In the last decades, the class of Ti-rich TiAl-based intermetallic materials has replaced many contemporary alloys till $900^{\circ} \mathrm{C}$. Due to higher oxidation resistance, $20 \%$ lower density and higher (about $150^{\circ} \mathrm{C}$ more) operating temperature possibility of Al-rich TiAl alloys over Ti-rich side, phases from the Al-rich region of this alloy system are considered to be highly potential candidates for high temperature structural applications. Although there are a lot of works about Ti-rich alloys, however, investigation from the Al-rich side is very limited. This work reviews the class of Al-rich TiAl alloys in terms of phases, microstructures, morphology, deformation mechanisms, mechanical behaviors along with a possible micromechanical modeling approach. Single crystal like Ti-61.8at.\%Al alloy from the Al-rich family has been chosen as an example for modeling high temperature anisotropy and tension-compression asymmetry. A possible comparison with Ti-rich side is also presented.
\end{abstract}

Keywords: Al-rich TiAl alloy, Crystal viscoplasticity, High temperature anisotropy, Tension-compression asymmetry

\section{Introduction and background \\ The family of Ti-Al alloys}

The generation of TiAl based intermetallic alloys represent an important class of high temperature structural materials providing a unique set of physical and mechanical properties that can lead to substantial rewards in aircraft engines, industrial gas turbines, and automotive industries (Appel et al. 2016; Austin 1999; Lapin 2009). In the last decades, it has replaced many contemporary metals and alloys till $800{ }^{\circ} \mathrm{C}$. A recent version of polysynthetically twinned (PST) single crystals like lamellar intermetallic Ti-45Al-8Nb has been proposed to be used till $900{ }^{\circ} \mathrm{C}$ (Chen et al. 2016). The growing application has also been extended to petroleum, medical, and defense industries (Khan et al. 2012; Tuninetti et al. 2015). Since 1970 s, this alloy system has been widely recognized as a possible basis for novel lightweight materials for high temperature applications (Zambaldi 2010). Experts are convinced that the alloy system has immense potential

${ }^{*}$ Correspondence: helal.chowhury@ovgu.de

'Graduate School for 'Micro-Macro Interactions in Structured Media and Particle Systems', Otto-von-Guericke University, 39106 Magdeburg, Germany Full list of author information is available at the end of the article that could revolutionize the world of aviation. According to some experts, Titanium Aluminides are the only promising alternatives in areas where heavy nickel alloys still prevail (Hautmann 2013; Xu et al. 2016). These alloys exhibit impressive material properties such as very good strength, high specific yield strength and stiffness, good oxidation and ignition resistance combined with good creep properties at high temperatures, fracture toughness, corrosive resistance, low density, high thermal capability, and biocompatibility, etc. (Appel et al. 2016; Khan et al. 2012; Tuninetti et al. 2015). Sufficient strength at high temperature and ductility at ambient temperature are crucial issues for these lightweight alloys. It is to be noted that the highly successful and potential alloys from this family are processed in lamellar structure as it is a key morphology. The class of Ti-rich lamellar alloys $\left(\gamma-\mathrm{TiAl}+\alpha_{2}-\mathrm{Ti}_{3} \mathrm{Al}\right)$ are already in many industrial applications fulfilling strength and ductility requirements at high temperature. For temperatures up to $1050{ }^{\circ} \mathrm{C}$, phases from the $\mathrm{Al}$-rich region of this alloy system are considered to be highly potential candidates for structural applications. Based on its higher aluminum content, $\mathrm{Al}$ rich $\mathrm{TiAl}_{2}$ phase is expected to have a lower density and 
better oxidation resistance than $\mathrm{TiAl}$ and $\alpha_{2}-\mathrm{Ti}_{3} \mathrm{Al}$, potentially making it a very attractive elevated temperature alloy constituent (Benci et al. 1995). The Al-rich Ti-Al alloys with $\mathrm{Al}$-contents exceeding 54at.\% $\mathrm{Al}$ are of special interest because they are expected to form protective $\mathrm{Al}_{2} \mathrm{O}_{3}$ scales instead of titanium oxides (Palm et al. 2002). In short, due to better oxidation resistance, $20 \%$ lower density and higher (about $150{ }^{\circ} \mathrm{C}$ more) operating temperature possibility of $\mathrm{Al}$-rich $\mathrm{Ti}-\mathrm{Al}$ alloys over Ti-rich side, they have recently become a focus of interest (Austin 1999; Palm et al. 2012; Sturm et al. 2009).

Generally Al-rich phases in the TiAl alloy family make the alloy brittle. Kad and Fraser (1994) reported that the Ti-rich $\gamma$-TiAl alloys are significantly ductile at high temperature because of no Al-rich brittle phases. In $\mathrm{Ti}-62.5 \mathrm{at} . \% \mathrm{Al}$, plate like $r-\mathrm{TiAl}_{2}$ type precipitates in the $\gamma$ matrix interrupt the motions of dislocations and retard the improvement in ductility below $1200{ }^{\circ} \mathrm{C}$ (Umakoshi et al. 1999). Fujiwara et al. (1990) mentioned that the cause of brittleness might be the partial dislocation $1 / 6<112$ ], which is a constituent of the $<011$ ] type superlattice dislocation. Chakravadhanula et al. (2011) mentioned that the refractory elements like $\mathrm{Nb}$ can improve tensile ductility as well as creep resistance of the Ti-Al alloys. Besides the beneficial effect of lamellar microstructures in improving mechanical properties, the fracture toughness, elevated temperature strength and oxidation resistance are further enhanced by the addition of $\mathrm{Nb}$ (Chakravadhanula et al. 2011). Considering Ti-62.5at.\% $\mathrm{Al}$ alloys containing $\mathrm{Al}_{5} \mathrm{Ti}_{3}$ precipitates in the $\mathrm{L} 1_{0}$ matrix, Appel et al. (2011) reported that the strong hardening is mainly caused by the antiphase boundaries that provide additional resistance to subsequent glide processes. This indicates that some dislocations in TiAl are permanently locked during the high temperature deformation (Appel et al. 2011).

\section{High temperature plastic anisotropy and and tension- compression asymmetry of TiAl alloys}

Anisotropy of inelastic behaviors, or in a more broad sense, the dependence of inelastic behaviors on the type of loading and direction is common for many high-temperature materials (Naumenko and Altenbach 2016). Important features of plastic anisotropy and asymmetry can be related to different length scales, like grain/subgrain scale, phase/lamellar scale, crystal lattice scale, dislocations and atomic scales, etc. Privileged crystallographic orientation or texture development can be associated with grain scale. Similarly many other origins of the anisotropy like defects inclusions-cavities in metals and multiphase alloys, directional distribution of a particular phase, anisotropy of individual grains, etc., can be related to different scale dependent phenomena. In order to understand different macroscopic behaviors including the plastic anisotropy and asymmetry in Ti-Al alloys, it is necessary to understand their origins at the lower length scales. Regular misfit dislocations along the lamellar interfaces, formation of faulted dipoles of superdislocations, changes in deformation modes due to the appearance of some superstructures, domination of climb at high temperature, etc., for the Al-rich TiAl family are few of them at the smaller scales. Various macroscopic behaviors of this family, like anomalous yielding and hardening, recovery, increasing brittleness with the increase of $\mathrm{Al}$-content, etc. are also deserved to be investigated in order to understand different inelastic phenomena. This knowledge is in turn instrumental to the understanding of the mechanisms responsible for the anomalous behavior, plastic anisotropy and tension compression asymmetry, etc. (Gregori and Veyssiere 2000). In general, it is believed that the plastic behaviors in Al-rich TiAl alloys depend on the formation of superstructural phases and the activated slip systems varied (Nakano et al. 1999).

Tension-compression asymmetry (TCA) or strength differential has a wide range of effects in mechanical properties. Different asymmetric behaviors and their detrimental effects in various practical applications can be found in the literature, e.g. Chowdhury et al. (2017c). Tensile cases are found to be stronger than that of compression in high strength Ti-3Al-2.5V alloys ( $\mathrm{Li}$ et al. 2016). However, the opposite trend is observed in Ti$6 \mathrm{Al}-4 \mathrm{~V}$ (Tuninetti et al. 2015). Various microstructure and mechanism dependent observations can be found while investigating the origin of asymmetry. Due to non Schmid effects (Salehinia and Bahr 2014) and twinning, the material with HCP (hexagonal closed pack) structure would exhibit higher asymmetry than that of BCC/FCC materials. This asymmetry originates from the differences in dominant deformation modes associated with tension and compression (Leng et al. 2016; Liu et al. 2016). For example, shear in one direction can produce twinning while shear in the opposite direction cannot, which results TCA (Vinogradov et al. 2015), for which CRSS differs based on the loading directions. Directionality of twinning, as the main factor of asymmetry, is also discussed in Kabirian and Khan (2015); Stewart and Cazacu (2011); Yoon et al. (2014).

\section{Objective of this study}

Even though the anisotropy and asymmetry in Ti-rich side have been investigated for some single-crystal and polycrystalline alloys, the lamellar orientation dependence of the plastic anisotropy and tension/compression asymmetry in Al-rich side is not very well documented, either theoretically or experimentally. In general, literature on the Al-rich part is very limited especially on the modeling of deformation behaviors. One important study from the Al-rich side is Zupan and Hemker 
(2003) with $55.5 \% \mathrm{Al}$, where asymmetry is investigated for different loading direction, temperature, orientations which displayed anomalous yielding and a pronounced tension/compression asymmetry. Rate dependent asymmetric phenomena of such alloys is especially important at high homologous temperature because of the appearance of one or more long period superstructures along with anomalous behaviors and subsequent activation of various deformation modes. To understand the combined effect of the lamellar morphology and long period superstructure is also of great interest. Based on the available literature, this study summarizes the important deformation features of the Al-rich family along with a comparative view with Ti-rich alloys, where applicable. Additionally this work also summarizes the recent works on the crystal plasticity modeling of Al-rich alloys with long period superstructures (LPS). Directionally solidified such lamellar material is expected to be highly anisotropic due to the presence of LPS and the preferred orientations of the lamellar colonies as like PST TiAl (Lebensohn et al. 1998). The main content of this work can be divided into two parts. In the first part, the current understanding of the Al-rich side has been summarized which includes the phases, ordering and their stability, microstructural and morphological state, deformation mechanisms, and mechanical behaviors, etc. Then the second part presents crystal plasticity based modeling approach combining the plastic anisotropy and asymmetry at high homologous temperature considering an important single crystal like alloy. Necessary experimental data, mathematical framework, model calibration, and model prediction, etc are also highlighted.

\section{Review}

Phases in the Al-rich Ti-Al alloy system: ordering and their stability

\section{Phases in the Al-rich side}

Three different stable phases are possible in multiphase $\mathrm{Ti}-\mathrm{Al}$ alloy system, these are $\gamma-\mathrm{TiAl}, \alpha_{2}-\mathrm{Ti}_{3} \mathrm{Al}$ and $r-\mathrm{TiAl}_{2}$. With melting point of $1463{ }^{\circ} \mathrm{C}, \gamma$-TiAl ( $1_{0}$-type) has a wide solubility range from the near stoichiometry to the Al-rich side (Braun and Ellner 2001; Nakano et al. 1999). In the near stoichiometric Ti-rich side, alloys mostly consist of two phases, $\gamma$-TiAl and $\alpha_{2}-\mathrm{Ti}_{3} \mathrm{Al}$. The $\gamma$-phase consists of face centered tetragonal (with $\mathrm{c} / \mathrm{a}=1.02$ ) lattice and $\alpha_{2}$-phase has hexagonal closed pack (HCP) crystal structures. Beyond the stoichiometric composition especially from 54at.\% $\mathrm{Al}$ content, depending on the $\mathrm{Al}$ content and annealing condition, one or more Al-rich phases mostly with $\gamma$-matrix phase are emerged (Hayashi et al. 2002). Along with stable $\gamma$-TiAl matrix phase, other precipitate phases are mostly metastable with long range order of $\mathrm{L} 1_{0}$-type structure. Among them, $\mathrm{Al}_{5} \mathrm{Tl}_{3}$ and $h-\mathrm{Al}_{2} \mathrm{Ti}$ are widely observed as metastable phases. Two superstructure phases, $\mathrm{Al}_{5} \mathrm{Tl}_{3}$ and $h-\mathrm{Al}_{2} \mathrm{Ti}$, are frequently observed in as-cast and low-temperature-annealed Al-rich TiAl alloys (Stein et al. 2001). The $\mathrm{Al}_{5} \mathrm{Tl}_{3}$ phase rapidly dissolves above $900{ }^{\circ} \mathrm{C}$ and $h-\mathrm{Al}_{2} \mathrm{Ti}$ remains as metastable phase at least up to $1200{ }^{\circ} \mathrm{C}$. Annealing of Ti-58.0at.\%Al below $800{ }^{\circ} \mathrm{C}$ results an island like $\mathrm{Al}_{5} \mathrm{Tl}_{3}$ phase developed in the $\mathrm{L} 1_{0}$ matrix, which in turn completely dissolves by annealing at higher temperature (Hata et al. 2002a; Nakano et al. 1999), and ultimately transforms fully into $h-\mathrm{Al}_{2} \mathrm{Ti}$ with the increasing of $\mathrm{Al}$ concentration, at least till Ti-62.5at.\%Al (Nakano et al. 2004). In general, precipitates of $\mathrm{Al}_{2} \mathrm{Ti}$, alone or with other phases, are found in the composition range of $56-75$ at.\%Al. This $r-\mathrm{Al}_{2} \mathrm{Ti}$ superstructure phase is generally stable below $1150{ }^{\circ} \mathrm{C}$. When the $\mathrm{Al}$ composition is higher than 60 at. $\%$, this phase is appeared with significant volume fractions maintaining semi-coherence to the $\mathrm{L} 1_{0}$ matrix, sometimes with $\mathrm{Al}_{5} \mathrm{Ti}_{3}$ superstructure. The density of the $r-\mathrm{TiAl}_{2}$ phase is $3.53-3.54 \mathrm{~g} / \mathrm{cm}^{3}$, lower than $\gamma-\mathrm{TiAl}$ and $\alpha_{2}-\mathrm{Ti}_{3} \mathrm{Al}$ (Benci et al. 1995). The $\mathrm{Al}_{5} \mathrm{Ti}_{3}$ phase can be eliminated by selecting suitable heat treatment parameters. In Ti-62.5at.\%Al alloys, annealed at temperatures below $1200{ }^{\circ} \mathrm{C}$, the $r$ $\mathrm{TiAl}_{2}$ phase is finally formed as an equilibrium phase, but the ordering of $\mathrm{Al}_{5} \mathrm{Ti}_{3}$ and subsequently $h-\mathrm{TiAl}_{2}$ often proceeds prior to precipitation of $r-\mathrm{TiAl}_{2}$ (Hayashi et al. 2002). A recent study on the phases and their evolution for 59.4 to 60.4 at.\%Al contents depending on the processing and annealing condition can be found in Palm et al. (2012).

All of the three superstructure phases consist of face centered ordered superstructures of $\gamma$-TiAl. The $h-\mathrm{TiAl}_{2}$ phase is similar to threefold face centered structure while $r$-phase is six fold and $\mathrm{Al}_{5} \mathrm{Tl}_{3}$ superstructure is equivalent to sixteen face centered lattice units. These long-period superstructures have different lattice periodicity, e.g. four-fold periodicity along the a- and b-axes in the $\mathrm{Al}_{5} \mathrm{Tl}_{3}$ superstructure; three-fold periodicity along the $\mathrm{b}$ - axis in the $h-\mathrm{TiAl}_{2}$; and sixfold periodicity along the c-axis in the $r-\mathrm{TiAl}_{2}$ (Nakano et al. 1999), as shown in Fig. 1 . In the $h-\mathrm{TiAl}_{2}$ and $r-\mathrm{TiAl}_{2}$ superstructures, the periodicities of $\mathrm{Al}$ layers are different.

There is consistent indication that the superstructure phases formed in the Al-rich $\gamma$-TiAl often exhibit fine microstructures with short-range order (SRO), antiphase domain boundaries, and so on in certain ranges of $\mathrm{Al}$ concentrations and temperatures (Gregori and Veyssiere 1999; Hata et al. 2002b; Nakano et al. 2002b; Stein et al. 2001). This is one of the most characteristic features of the long-period ordering phenomena in Al-rich TiAl (Hata et al. 2004a). For both 62.5 and $60 \mathrm{at} \% \mathrm{Al}$ alloys, $\mathrm{Al}_{5} \mathrm{Ti}_{3} \mathrm{SRO}$ structures are found in Ti-rich (002) layers of the $\mathrm{L}_{0}$ ordered $\gamma$-TiAl matrix along with long-range order (LRO) phase up to about $800{ }^{\circ} \mathrm{C}$. At higher temperature, SRO 


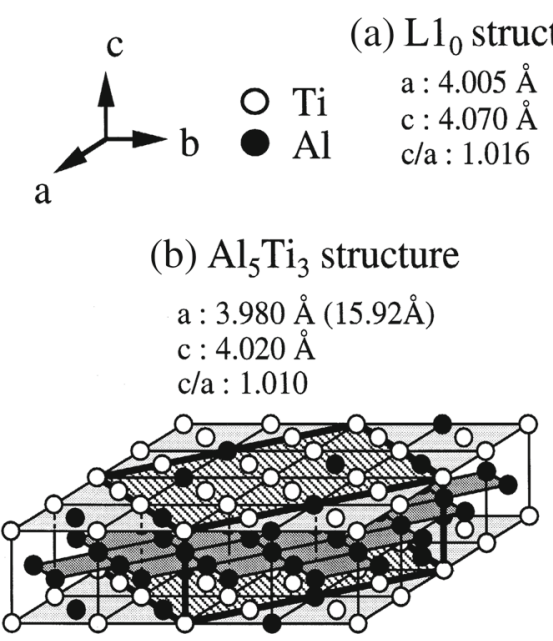

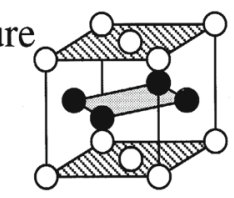

(c) $\mathrm{h}-\mathrm{Al}_{2} \mathrm{Ti}$ structure a : $3.959 \AA$

b : $4.032 \AA(12.09 \AA)$

c : $4.032 \AA$

c/a $: 1.018$

$\mathrm{c} / \mathrm{b}: 1.000$

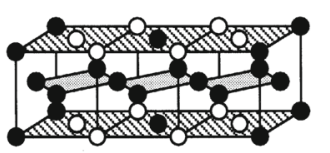

(d) $\mathrm{r}-\mathrm{Al}_{2} \mathrm{Ti}$ structure

a : $3.972 \AA$

c : $4.051 \AA(24.31 \AA)$

$\mathrm{a} / \mathrm{c}: 1.020$

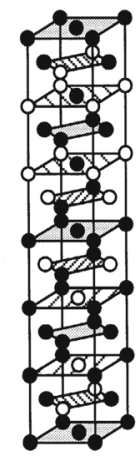

Fig. 1 Crystal structures with lattice parameters for different phases appearing in the Al-rich TiAl alloys. a $L 1_{0}$ structure, b $\mathrm{Al}_{5} \mathrm{Tl}_{3}$ superstructure, c $h$-TiAl 2 superstructure, $\mathbf{d} r-\mathrm{TiAl}_{2}$ superstructure. The figure is taken from Nakano et al. (1999)

state becomes unstable in the course of the phase transformation from the $\mathrm{Al}_{5} \mathrm{Ti}_{3}$ to the $h-\mathrm{TiAl}_{2}$ phase (Hata et al. 2002a). In spite of a number of studies, structural details and formation processes of the fine microstructures are still controversial in many cases, owing to insufficient experimental information at the atomic scale (Hata et al. 2004a).

\section{Ordering and stability}

So far we know, the $r-\mathrm{Al}_{2} \mathrm{Ti}$ is stable at about 58 to 62.5at.\% Al in the temperature range between $700{ }^{\circ} \mathrm{C}$ and $1200{ }^{\circ} \mathrm{C}$ (Palm et al. 2002, 2012; Stein et al 2001; Zhang et al. 2001). The volume fraction of the constituent $r-\mathrm{TiAl}_{2}$ phase depends on the alloy composition and annealing temperature, and decreases with increasing Ti content and increasing temperature. The compositions ranging from $\mathrm{Ti}-54.7 \mathrm{at} . \% \mathrm{Al}$ to $\mathrm{Ti}-62.5 \mathrm{at} . \% \mathrm{Al}$ annealed at $1200{ }^{\circ} \mathrm{C}$, the $\mathrm{Al}_{5} \mathrm{Ti}_{3}$ long-period superstructure is embedded in the host $\mathrm{L} 1_{0}$ matrix, then transformed gradually into $h-\mathrm{TiAl}_{2}$ with the increasing $\mathrm{Al}$ concentration, and finally, there is a complete transformation into $h-\mathrm{TiAl}_{2}$ for Ti-62.5at.\%Al alloy (Nakano et al. 2004). Since the periodicity of $\mathrm{Al}$ layers in the $r-\mathrm{TiAl}_{2}$ phase is different from that in the $\mathrm{L}_{0}$ structure (the $\mathrm{Al}_{5} \mathrm{Ti}_{3}$ and $h$ $\mathrm{TiAl}_{2}$ phases have stacking periodicity analogous to that in the $\mathrm{L} 1_{0}$ ), a complex diffusion process is necessary for the nucleation and growth in the phase transformation to $r-\mathrm{TiAl}_{2}$ phase (Nakano et al. 1999). Therefore, the $\mathrm{Al}_{5} \mathrm{Ti}_{3}$ and $h-\mathrm{TiAl}_{2}$ phases appear prior to the formation of the final equilibrium $r-\mathrm{TiAl}_{2}$ phase. At first the $\mathrm{Al}_{5} \mathrm{Ti}_{3}$ phase formed rapidly and then the metastable $h-\mathrm{TiAl}_{2}$ phase appeared prior to that of the $r-\mathrm{TiAl}_{2}$ phase (Nakano et al. 1999), which has been confirmed in Ti-60at.\%Al and $\mathrm{Ti}-62.5 \mathrm{at} . \% \mathrm{Al}$ during annealing below $800^{\circ} \mathrm{C}$.

Further ordering of long-period superstructures may occur in the Al-rich region depending on the Al composition and heat treatment (Nakano et al. 2004). Annealing of Ti-58at.\%Al at $1000{ }^{\circ} \mathrm{C}$ for $1 \mathrm{~h}$, only the $\mathrm{r}-\mathrm{Al}_{2} \mathrm{Ti}$ phase is remained in the $\mathrm{L} 1_{0}$ matrix. In Ti-62.5at.\%Al alloy, $\mathrm{Al}_{5} \mathrm{Ti}_{3}$ were obtained with the matrix phase by the floating zone method and subsequent heat treatment at $750^{\circ} \mathrm{C}$ for $48 \mathrm{~h}$ (Nakano et al. 2002a). Moreover, annealing at $930{ }^{\circ} \mathrm{C}$ results a nice lamellar morphology of the $\gamma$ and $r$ phases (Nakano et al. 1999), as shown in Fig. 2. Single-phase single crystal of only $\mathrm{Al}_{5} \mathrm{Ti}_{3}$ can also be generated over a wide temperature and time range of annealing although the antiphase boundaries (APBs) based on the $\mathrm{Al}_{5} \mathrm{Ti}_{3}$-type ordering exist (Hayashi et al. 2002; Nakano et al. 2002a). First annealing of $\mathrm{Ti}-62.5 \mathrm{at} . \% \mathrm{Al}$ at $1200{ }^{\circ} \mathrm{C}$ and then at

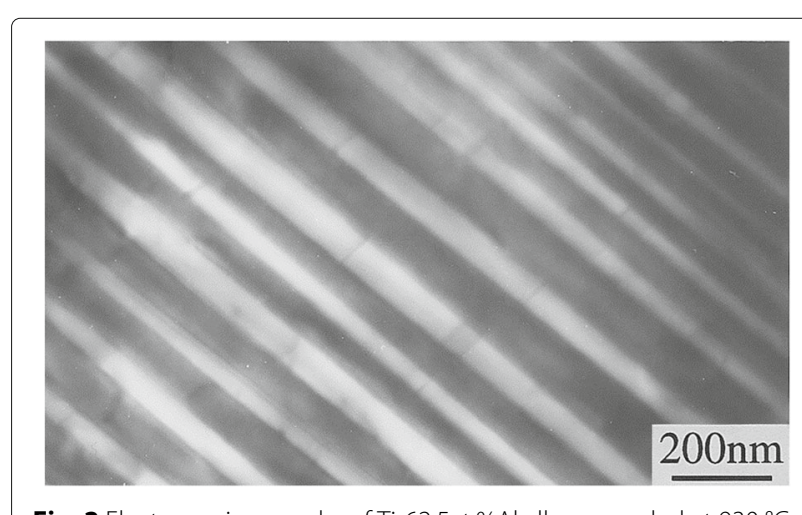

Fig. 2 Electron micrographs of Ti-62.5at.\%Al alloy annealed at $930^{\circ} \mathrm{C}$, taken from Nakano et al. (1999) 
$750{ }^{\circ} \mathrm{C}$ for $48 \mathrm{~h}$ results $\mathrm{Al}_{5} \mathrm{Ti}_{3}$ single-phase single crystals (Nakano et al. 2004). More interestingly, one or more phases can be completely eliminated by the choice of a set of suitable heat treatment parameters. From Ti-60at.\%Al and Ti-62.5at.\%Al crystals containing $\mathrm{Al}_{5} \mathrm{Ti}_{3}$ and $r-\mathrm{TiAl}_{2}$ phases embedded in the $\gamma$-TiAl matrix, the plate like $r$ $\mathrm{TiAl}_{2}$ phase can be eliminated by annealing for $1 \mathrm{~h}$ at 1100 and $1200{ }^{\circ} \mathrm{C}$, respectively (Hata et al. 2002a). The $r-\mathrm{TiAl}_{2}$ is only found to be stable in $\mathrm{Ti}-62.5 \mathrm{at} . \% \mathrm{Al}$ if the alloy is annealed at temperatures below $1200{ }^{\circ} \mathrm{C}$ (Hayashi et al. 2002). The $\mathrm{Al}_{5} \mathrm{Ti}_{3}$ superstructural spots start disappearing and the $h-\mathrm{TiAl}_{2}$ spots become dominant after $800{ }^{\circ} \mathrm{C}$ (Hayashi et al. 2002). So the Ti-62.5at\%Al alloy exhibits a clear annealing temperature dependence of the long-period superstructure phases: an $\mathrm{Al}_{5} \mathrm{Ti}_{3}$ ordered state below $900{ }^{\circ} \mathrm{C}, \mathrm{Al}_{5} \mathrm{Ti}_{3}$ with an SRO state and $h$ $\mathrm{TiAl}_{2}$ or $r-\mathrm{TiAl}_{2}$ till $1200^{\circ} \mathrm{C}$ and an $h-\mathrm{TiAl}_{2}$ ordered state above $1200{ }^{\circ} \mathrm{C}$ (Hata et al. 2002c, 2003, 2004a; Hayashi et al. 2002). More detail about ordered cluster of different SRO states with different shapes, and the SRO-LRO transition in Ti-62.5at.\%Al can be found in Hata et al. (2002b, 2003).

As reported previously, the plate-like $r-\mathrm{TiAl}_{2}$ phase in as-grown Ti-62.5at.\%Al single crystals were easily annihilated by annealing at $1200{ }^{\circ} \mathrm{C}$ for $1 \mathrm{~h}$, while small $h-\mathrm{TiAl}_{2}$ particles were homogeneously distributed in the $\mathrm{L} 1_{0}$ matrix. Subsequent annealing at temperatures between 500 and $900{ }^{\circ} \mathrm{C}$ for $1 \mathrm{~h}$ did not produce $r$ $\mathrm{TiAl}_{2}$ yet, although both $r-\mathrm{TiAl}_{2}$ and $\mathrm{L} 1_{0}$ are known to be stable phases in this annealing temperature range (Hayashi et al. 2002). So the $r-\mathrm{TiAl}_{2}$ and $h-\mathrm{TiAl}_{2}$ phases are believed to be final stable structures in the temperature range below and above $1200{ }^{\circ} \mathrm{C}$, respectively, but some preceding phases appear prior to the ordering of the final superstructure (Hayashi et al. 2002). Metastable nature of the $h-\mathrm{TiAl}_{2}$ phase is observed at various annealing temperatures below $1200{ }^{\circ} \mathrm{C}$ (Hayashi et al. 2002). The precipitation of $h-\mathrm{TiAl}_{2}$ was accelerated by increasing annealing temperature. Annealing time is also a very important factor in the stability of superstructures. For instance, annealing at $900{ }^{\circ} \mathrm{C}$ for $1 \mathrm{~h}$, the $h-\mathrm{TiAl}_{2}$ phase is formed with lamellar morphology along with the matrix phase whereas further annealing may introduce $r-\mathrm{TiAl}_{2}$ into this crystals (Hayashi et al. 2002). Single crystals of Ti-54.7at.\%Al, Ti-56.0at.\%Al, Ti-58.0at.\%Al, Ti-60.0at.\%Al and $\mathrm{Ti}-62.5 \mathrm{at} . \% \mathrm{Al}$ produced by different annealing temperatures and times along with a comparative study can be found in Nakano et al. (2004). An overview of different alloy phases with appeared LPS in Al-rich region has been documented according to $\mathrm{Al}$ concentration and heat treatment in (Braun and Ellner 2001; Palm et al 2002; Stein et al 2001). Further works on the appeared phases are Zhang et al. (2001) and Palm et al. (2012) with special emphasize on Ti-62at.\%Al and Ti-60at.\%Al. In spite of a number of studies in the Al-rich side, there are many uncertain points remaining which are still not fully understood. The most controversial area of $\mathrm{Ti}-\mathrm{Al}$ binary phase diagram ranges between 55 and 77 at.\%Al, and 900 to $1450{ }^{\circ} \mathrm{C}$ (Batalu et al. 2006). The TiAl-TiAl region with $\mathrm{Al}$ contents from 56 to 65 at.\% Al is still not resolved satisfactorily (Palm et al. 2002). Some other unresolved issues are the precise morphological stability of the microstructure, the dynamics of the microstructural changes, the stability and the ordering mechanisms, and accurate precipitation processes etc. (Hata et al, 2008, Koyama et al, 2000, Nakano et al, 2012). This may be due to the fact that the long-period ordering is quite sensitive to the $\mathrm{Al}$ concentration and annealing conditions (Hata et al. 2004b).

\section{Lamellar alloys: Ti-rich vs. Al-rich with LPS}

It is worth to mention that the lamellar structure is a key morphology for many complex engineering materials ( $\mathrm{Li}$ and Weng 1998). Such a lamellar structure is expected to have a significant influence on the deformation behaviors (Fujiwara et al. 1990). This kind of microstructures generally exhibit improved ductility, fracture toughness and creep resistance in comparison to their monolithic constituents (Grujicic and Batchu 2001; Sturm 2010). Current activities to improve the properties of $\gamma$-TiAl based alloys mainly focus on improving strength and creep resistance at high temperatures and a better oxidation behavior (Palm et al. 2002), for which Alrich alloys deserve special attention. For a lamellar alloy, there are mainly four components of shear stress, from which one or more are responsible for yield and plastic anisotropy depending on the microstructural and morphological combination. These four components are: 1) lattice resistance of the material or Peierls stress which depends on the lattice type and lattice plane, 2) stress to operate dislocation sources or the Frank Read stress, 3) stress required to transmit dislocations through interfaces or the Hall-Petch stress, and 4) internal stress generated by lattice mismatches in the lamellar interfaces. Even though deformation modes along the lamellar plane is easy or soft mode, and across the lamellae is hard, these stresses have very different effects on soft and hard modes of deformation and account for some of the plastic anisotropy. For the complex hardening mechanism of individual slip system, the effect of the Hall-Petch stress is believed to be the dominant one (Kad et al. 1992).

From the rough range of $58-65$ at.\% $\mathrm{Al}$ content, there is a possibility of generating lamellar structure with $\gamma$ and $r$ phases along with other minor phases. Further interest is on alloys with about 62at.\%Al due to the possibility of generating lamellar and stable phases of $\gamma$-TiAl $+r$ $\mathrm{TiAl}_{2}$ microstructures (like in Fig. 2), which may enhance 
prospects of possible alloy developments as Ti-rich side. The $\gamma$-TiAl based Ti-rich alloys derive their advantageous creep properties from the lamellar $\gamma$-TiAl $+\alpha_{2}-\mathrm{Ti}_{3} \mathrm{Al}$ microstructures. There is a number of studies on the choice of the heat treatment parameters for which lamellar alloys with stable phases can be generated. A summary of some of the available studies on phases and morphology appeared in alloys with 58,60,62, 64at.\%Al content for different heat treatment parameters can be found in Palm et al. (2002); Stein et al. (2001). Braun and Ellner (2001) investigated alloys with 60-64at.\%Al contents and showed that the lamellar structure can be generated by the choice of the annealing temperature range from 800$1100^{\circ} \mathrm{C}$. With the increase of Al-content, higher annealing temperature might be necessary. An elaborated summary on this issue can be found in Palm et al. (2002). Another detailed study on the formation of lamellar structures can be found in Zhang et al. (2001), where phases, microstructures, lamellar spacing, lamellar coarsening, and related heat treatment parameters etc. are also discussed. Special emphasize is given on 62at.\% $\mathrm{Al}$ content, which shows that $950{ }^{\circ} \mathrm{C} / 200 \mathrm{~h}, \mathrm{WQ}$ are the most favorable parameters for generating coarse and fully lamellar alloy of $\gamma$-TiAl + $r$ - $\mathrm{TiAl}_{2}$ phases.

As mentioned earlier, over a wide solubility range in off-stoichiometric Al-rich region, long-period superstructures appear depending on the $\mathrm{Al}$ concentration and annealing conditions e.g. temperature and time (Hata et al. 2008; Nakano et al. 2012). They play an important role in operative deformation modes and configuration of dislocations in $\mathrm{Al}$-rich $\mathrm{TiAl}$, depending on the $\mathrm{Al}$ concentration. Plastic deformation behavior and activated slip systems in Al-rich TiAl crystals are closely related to the formation of superstructures (Hayashi et al. 2002). Anomalous strengthening and slip-plane transition for the $1 / 2<110$ ] ordinary dislocations at temperatures around the peak stress in the yield stress-temperature curve are also thought to be influenced by the $\mathrm{Al}_{5} \mathrm{Ti}_{3}$ type ordering in Ti-62.5at.\%Al (Hayashi et al. 2002). Fourfold ordinary dislocations, for example, often move as a group in the $\mathrm{Al}_{5} \mathrm{Ti}_{3}$ superstructure embedded in the $\mathrm{L} 1_{0}$ matrix. Many studies have indicated that dislocation motion in $\mathrm{Al}$-rich $\mathrm{TiAl}$ is strongly influenced by the appearance of some long-period superstructures (Nakano et al. 2012).

\section{Deformation mechanisms: Ti-rich vs. Al-rich lamellar TiAl}

The deformation modes of TiAl based alloys strongly depend on their microstructure, alloy composition (e.g. Al concentration), orientation, impurity content of interstitial atoms and deformation temperature (Marketz et al. 2003; Nakano et al. 1996). It is now well established that the fundamental deformation mechanisms of Ti-rich $\gamma-\mathrm{TiAl}+\alpha_{2}-\mathrm{Ti}_{3} \mathrm{Al}$ based alloys consist of ordinary slip $1 / 2<110]\{111\}$, superdislocation slip $<101]\{111\}$ as well as twin systems $1 / 6<112]\{111\}$ (Feng and Whang 2000; Fujiwara et al. 1990; Gregori and Veyssiere 1999; Kawabata et al. 1985). Often $1 / 2<112]\{111\}$ type superdislocation slip is also observed as reported by Feng and Whang (2000); Marketz et al. (2003). Under most conditions deformation occurs along the $\{111\}$ planes by the glide of ordinary dislocations with the Burgers vector $1 / 2<110$ ] and superdislocations with $<101$ ] and $1 / 2<112]$. Below the peak temperature, ordinary slips are dominantly operative for most loading orientations. As the $\gamma$-phase is considerably weaker than the $\alpha_{2}$-phase, mostly it is assumed that the plastic deformation parallel to the interface is controlled by the softer $\gamma$-TiAl phase, while deformation component normal to these boundaries is dominated by the harder $\alpha_{2}-\mathrm{Ti}_{3} \mathrm{Al}$ phase (Grujicic and Batchu 2001; Marketz et al. 2003). Although some authors previously considered ordinary dislocation slips and twinning are predominant than superlattice dislocations, later investigation shows that superdislocations are significant in some cases and there is clear evidence that superdislocations are kinematically necessary for plastic deformation (Werwer and Cornec 2006).

On the other hand, excess $\mathrm{Al}$ atoms in the Al-rich alloys may replace some $\mathrm{Ti}$ atoms on the (001) plane and form different ordered structures. As a result we observe three long-period superstructures of $r-\mathrm{Al}_{2} \mathrm{Ti}, h-\mathrm{Al}_{2} \mathrm{Ti}$ and $\mathrm{Al}_{5} \mathrm{Ti}_{3}$ and they are based on the face centered lattice. Such periodic ordering contributes to the deformation modes of these alloys. The work of Nakano et al. (2002a) is a good example in this regard. They found that the CRSS for $\{111\} 1 / 2<110]$ ordinary slip family is quite lower in $\mathrm{Al}_{5} \mathrm{Ti}_{3}$ single-phase single crystals than that in other $\mathrm{Al}$ rich TiAl crystals composed of $\mathrm{Al}_{5} \mathrm{Ti}_{3}$ precipitates and the $\mathrm{L}_{0}$ matrix (Nakano et al. 2002a). Analyzing $\mathrm{Al}_{5} \mathrm{Ti}_{3}$ single phase single crystals, they further reported that, almost all dislocations exist as a group of four dislocation segments with the same sign of $1 / 2<110$ ] Burgers vector. Three APBs are created between the $1 / 2<110$ ] dislocations, thus the group motion of four ordinary dislocations is most favorable for suppressing the effect of APBs, resulting in a stress drop in $\mathrm{Al}_{5} \mathrm{Ti}_{3}$ single-phase single crystals. In contrast, superlattice dislocations did not move as a group and glided independently in that single-phase single crystals (Nakano et al. 2002a). So it is clear that the plastic deformation behavior and activated slip systems in Al-rich TiAl crystals are closely related to formation of the respective superstructures (Hayashi et al. 2002). Fundamental deformation mechanisms of the Al-rich alloys compared to the Ti-rich side can be divided into the following points.

- Firstly, twinning is suppressed for most alloys and the dislocation motion is strongly influenced by the 
appearance of LPS in Al-rich TiAl alloys (Hayashi et al. 2001; Nakano et al. 2005). However, Inui et al. (1997) observed twinning in Ti-56at.\%Al alloys in the temperature range $800-1000{ }^{\circ} \mathrm{C}$.

- Secondly, in contrast to the ordinary slips in Ti-rich alloys, superlattice dislocations are mostly operative below the peak temperature in the Al-rich side. Analyzing Ti-54.5at.\%Al, Jiao et al. (1998) noted that a major part of the slip occurs via the $<011$ ] superdislocations in the temperature range below the peak. On the other hand, $\{111\}<101]$ superlattice slip is found to be a dominant system in Ti-54.7at.\%Al and 58.0at.\%Al single crystals at all the tested temperatures up to $900{ }^{\circ} \mathrm{C}$ (Nakano et al. 2002a). Nakano et al. (1996) reported that the $<101]$ superlattice dislocations were more often observed than other slip systems. Higher mobility of these dislocations than that of $1 / 2<110$ ] ordinary dislocations has been confirmed by analyzing many compounds in the composition range 52-60at.\%Al. They further explained that the CRSS for the ordinary dislocations rises sharply with increasing $\mathrm{Al}$ concentration, while the superlattice dislocations showed no strong sensitivity to the composition. Therefore, ordinary dislocations were dominantly operative in $\mathrm{Ti}-\mathrm{Al}$ alloys with near-stoichiometric composition, while the motion of superlattice dislocations controlled the plastic behavior of Al-rich $\mathrm{Ti}-\mathrm{Al}$. In Ti-52.6at.\%Al, the predominant deformation modes change from the ordinary slips to superslips due to the emergence of superstructure (Hayashi et al. 2001; Nakano et al. 2012). In some Al-rich TiAl single crystal, $1 / 2<112$ ] type superdislocations are also found to be mainly active at $800{ }^{\circ} \mathrm{C}$ (Kawabata et al. 1994). One important point is that the superdislocations with $1 / 2<112$ ] have been observed to be dissociated to form faulted dipoles during low-temperature deformation and this dissociation contributes to the strong hardening rate, while at a higher deformation temperature $\left(750^{\circ} \mathrm{C}\right.$ or more) these dislocations disappear (Viguier et al. 1995). However, Nakano et al. (1998) and Nakano et al. (2005) documented that the $1 / 2<110$ ] ordinary dislocations are always operative in the $\mathrm{L} 1_{0}$ structure like in Ti-rich side. Moreover, they glide on the $\{111\}$ planes independently in the matrix phase and as a pair in the superstructures of $r-\mathrm{Al}_{2} \mathrm{Ti}$ and $h-\mathrm{Al}_{2}$ in Ti-62.5at.\%Al. According to them, ordinary dislocations glide individually although slight threefold grouping is also encountered with the periodicity of $h-\mathrm{Al}_{2} \mathrm{Ti}$ (Nakano et al. 2004; 2005). The ordinary slips are operative and independent of the tested temperature and crystal orientation, is also reported in Nakano et al. (2002a).
- Thirdly, ordinary dislocations are suppressed by LPS. Nakano et al. (1999) found that the motion of $1 / 2<110$ ] ordinary dislocations was suppressed by the development of the $\mathrm{Al}_{5} \mathrm{Ti}_{3}$-type ordering with increasing $\mathrm{Al}$ composition. Nakano et al. (2002a) also found that the existence of the $\mathrm{L} 1_{0}$ matrix with the $\mathrm{Al}_{5} \mathrm{Ti}_{3}$ phase must be closely related to strengthening for the ordinary slip. So it is evident that the plastic deformation behavior and operative slip system in Al-rich off-stoichiometric TiAl crystals are very sensitive to formation of the long-period superstructures such as $\mathrm{Al}_{5} \mathrm{Ti}_{3}, h-\mathrm{Al}_{2} \mathrm{Ti}$ and $r-\mathrm{Al}_{2} \mathrm{Ti}$ (Nakano et al. 2002a). Nakano et al. (2005) concluded that with the addition of $\mathrm{Al},<101]$ slip becomes gradually favored at the expense of $1 / 2<110]$ ordinary slip as the energy of anti-phase boundaries engendered in $\mathrm{Al}_{5} \mathrm{Ti}_{3}$ by ordinary dislocations is higher than those created by $<101]$ superlattice dislocations. Because the isolated dislocations created extra APBs behind the dislocations, the pronounced frequency of APBs formation must have contributed to the rapid increase in the CRSS for ordinary slip (Nakano et al. 2012). This effect is manifested by a relatively sharp increase in the critical resolved shear stress (CRSS) till the peak temperature for $1 / 2<110$ ] ordinary slip relative to $<101$ ] slip. So the relative motion of ordinary dislocations is difficult compared to superlattice dislocations at lower temperature. Considering $\mathrm{Ti}_{50} \mathrm{Al}_{50}$ to $\mathrm{Ti}_{42} \mathrm{Al}_{58}$ alloys, for instance, the critical shear stresses resolved on ordinary and superslips increase by a factor of 4 and 1.5 , respectively (Gregori and Veyssiere 1999). Which means extra strengthening is achieved by increasing $\mathrm{Al}$, and mainly ordinary slips gets harder. In $\mathrm{Ti}-62.5 . \% \mathrm{Al}$, the CRSS of $1 / 2<110$ ] ordinary system increases with the growth of $h-\mathrm{Al}_{2} \mathrm{Ti}$ increasing $\mathrm{Al}$ concentration and annealing time. The CRSS for the same direction further increases with the further formation of superstructures within the $\mathrm{L} 1_{0}$ matrix. Like $\mathrm{Al}_{5} \mathrm{Ti}_{3}$ and $h-\mathrm{Al}_{2} \mathrm{Ti}$ phases, the $r-\mathrm{Al}_{2} \mathrm{Ti}$ precipitate suppresses the motion of $1 / 2<110$ ] ordinary dislocations resulting in significant strengthening (Umakoshi et al. 1999).

- Fourthly, transition of slip plane from $\{111\}$ to $\{110\}$ and (001). Jiao et al. (2001); Nakano et al. (1998) reported that a transition of predominance in slip plane from $\{111\}$ to (001) occurs near and above the peak temperature around $800{ }^{\circ} \mathrm{C}$ due to the anisotropy of anti-phase boundary energies on $\{111\}$ and (001) in the $r-\mathrm{Al}_{2} \mathrm{Ti}$ and $\mathrm{Al}_{5} \mathrm{Ti}_{3}$ phases created by $1 / 2<110$ ] ordinary dislocations (Jiao et al. 1998; Nakano et al. 1998). Hayashi et al. (2001) further reported that, with the presence of the $\mathrm{Al}_{5} \mathrm{Ti}_{3}$ superstructure, the transition of slip plane for 
$1 / 2<110]$ ordinary dislocations from $\{111\}$ to $\{110\}$ and/or $\{001\}$ occurred at and above the peak temperature.

- Fifthly, existence of the regular misfit dislocation network at the interfaces. As long as the lamellar phases in the matrix are very fine, the misfit dislocations were hardly observed in the interlamellar boundaries. Regular misfit Dislocations are increased with the coarsening of the lamellae (Zhang et al. 2001) due to discontinuous grain boundary migration as well as continuously by fault migration (Palm et al. 2012). Fully coarsened lamellar microstructures contain misfit dislocation networks at the interfaces with orthogonal burger vectors, which results activation of the slip systems along the interface plane (Lei et al. 2000; Zhang et al. 2001). Semi-coherent boundaries containing misfit boundary dislocations are formed at the interface of the $\mathrm{r}-\mathrm{Al}_{2} \mathrm{Ti} / \mathrm{L} 1_{0}$. This also suggests that strengthening is achieved by the $r-\mathrm{Al}_{2} \mathrm{Ti}$ (Nakano et al. 1998).

- Sixth and finally, complex deformation modes at and after the peak temperature. Inui et al. (1997) investigated Ti-56at.\%Al alloys from -200 to $1100{ }^{\circ} \mathrm{C}$ for seven different loading orientations. Till $700{ }^{\circ} \mathrm{C}$, it is found that the superlattice slips are operative for six orientations, while ordinary slips are operative only for a single case. At $800^{\circ} \mathrm{C}$, super slips are replaced by twinning for one orientation, other loading cases are same as before. At $900{ }^{\circ} \mathrm{C}$, ordinary slips are replaced by superslips for another loading case, rest are same as the case of $800^{\circ} \mathrm{C}$. The operative systems, so far, all belong to the $\{111\}$ planes. Surprisingly at $1000^{\circ} \mathrm{C}$, in addition to $\{111\}$ planes, ordinary and superslips are found to be operative for some orientations along $\{110\}$ and (001) planes. The summary is presented in Fig. 3.
So it can be summarized that, above the peak temperature, $1 / 2<110$ ] slip, twinning and $1 / 2<112$ ] superlattice slip can be considered to be operative depending on the alloy composition and orientation. Ordinary slip $1 / 2<110]$ occurs not only along the $\{111\}$ planes but also on (001) and $\{110\}$ planes for some orientations (Inui et al. 1997).

\section{Yield stress anomaly}

Anomalous yielding is a very important issue that has been reported in many papers and is not clearly understood for the TiAl alloy family. The slip systems operating in Al-rich $\gamma$-TiAl exhibit a pronounced anomalous increase of the critical stress with temperature. In this regard, Inui et al. (1997) is one of the finest contributions for Al-rich TiAl alloys. In Ti54.5at.\%Al single crystals, Jiao et al. (2001) observed that the Al-rich $\gamma$-TiAl alloys show yield stress anomaly (YSA) between $600-900{ }^{\circ} \mathrm{C}$ depending on the alloy composition, texture and grain size. There are some jog formation which is thought to be the cause of the YSA (Jiao et al. 2001). Investigating the Ti-56at.\%Al alloys with various loading orientations, Inui et al. (1997) reported that the yield stress varies with temperature in three stages. At low temperatures (the first stage), it decreases rapidly with increasing temperature followed by a plateau region up to about $600{ }^{\circ} \mathrm{C}$. Then the yield stress increases anomalously with increasing temperature and reaches a peak at $700-1000{ }^{\circ} \mathrm{C}$, depending on crystal orientation (the second stage). Above the peak, it again decreases rapidly with increasing temperature (the third stage). As mentioned earlier, in the first two stages, the major deformation mode is either ordinary or (101] superlattice slip depending on the crystal orientation. The CRSS for ordinary slip is considerably larger than that of $<101$ ] superlattice slip. The third stage is the highest-temperature stage where $1 / 2<110$ ] slip, twinning and $1 / 2<112$ ] superlattice slip are identified to be operative. Slip along $1 / 2<110]$

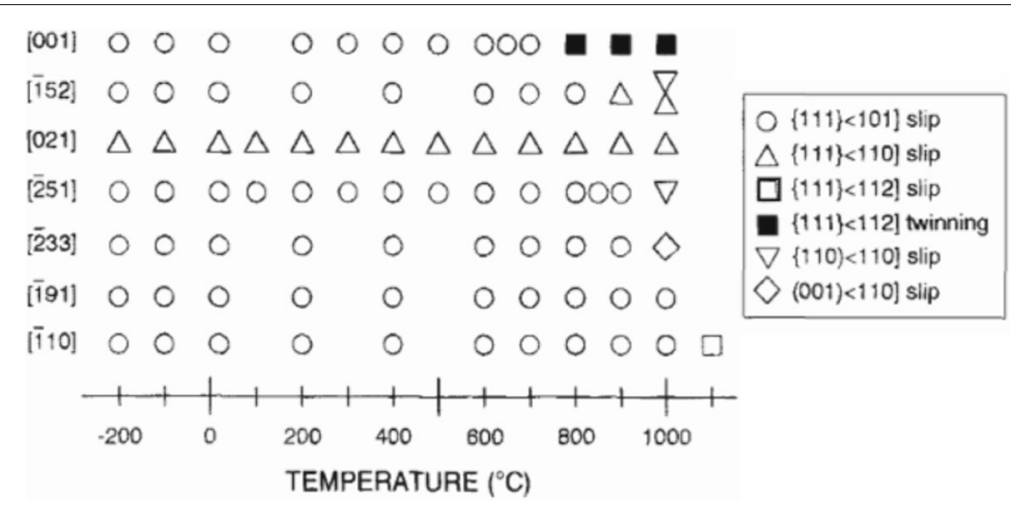

Fig. 3 Summary of the deformation modes for the seven different orientations investigated in wide temperature range from -200 to $1100{ }^{\circ} \mathrm{C}$ for Ti-56at.\%Al alloys. Different deformation modes are indicated by different symbols, [Courtesy: Inui et al. (1997)] 
occurs not only on $\{111\}$ but also on (001) and $\{110\}$, depending on the orientations (Inui et al. 1997). Similar trend has also been observed in alloys with 58-62.5at.\%Al, showing the peak of anomaly at $800^{\circ} \mathrm{C}$ (Nakano et al. 1998). Both the ordinary and <101] superlattice slips exhibit an anomalous increase in the critical resolved shear stress (CRSS). However, the extent of the anomaly associated with the ordinary slip is much smaller than that for the superlattice dislocation slip (Inui et al. 1997). Jiao et al. (1998) made the similar conclusion mentioning that the observed anomaly in the yield stress reflects mainly an anomaly for $<011]\{111\}$ slip. According to Feng and Whang (2000), both the $1 / 2<110]\{111\}$ and $<101]\{111\}$ slips are two dominant slip systems responsible for the plastic deformation and anomalous hardening in this material, and their presence strongly depends on temperature and applied stress direction. In $\mathrm{Al}_{5} \mathrm{Ti}_{3}$ single phase single crystals, superlattice slips do not exhibit an anomalous stress peak with $\mathrm{Al}$ concentration and thus anomalous strengthening does not appear in that alloys (Nakano et al. 2002a). In the case of the $<101]\{111\}$ superdislocation glide systems, Appel et al. (2011) noted that the yield stress anomaly can be attributed to the formation of thermally stable dislocation locks. They further reported that the anomalous hardening of the $1 / 2<110]\{111\}$ ordinary glide system is probably caused by the formation of an ordered superstructure e.g. $\mathrm{Al}_{5} \mathrm{Ti}_{3}$ phase. These results provide good supporting evidence that the yield stress anomaly can be strongly affected by minor phases present in Al-rich alloys (Appel et al. 2011). The yield stress of Ti-62.5at.\%Al was approximately twice as large as that of $\mathrm{Ti}-58 \mathrm{at} . \% \mathrm{Al}$ at and below $1100{ }^{\circ} \mathrm{C}$ where the $r-\mathrm{Al}_{2} \mathrm{Ti}$ precipitates still remained in Ti-62.5at.\%Al. This suggests that the strengthening is achieved by the $r-\mathrm{Al}_{2} \mathrm{Ti}$ precipitates (Nakano et al. 1998). For Ti-56at.\%Al, softening occurs with increasing temperature after $900{ }^{\circ} \mathrm{C}$, which could mean the decoupling of the anomalous hardening mechanism (Feng and Whang 2000). Interesting to note that the anomaly is not limited to the macroscopic yielding and microscopic CRSS, but also observed in the lattice parameters. Nakano et al. (1999) investigated three Al-rich alloys (Ti-58at.\%Al, Ti-60at.\%Al, Ti-62.5at.\%Al) with different annealing temperatures where it is observed that the ratio of the lattice parameters c/a has an anomalous trend of sudden decrease and increasing in the temperature range of 700$900{ }^{\circ} \mathrm{C}$. Some other works on the yield stress anomaly in Al-rich side are Gregori and Veyssiere (2001); Gregori et al. (2001); Jiao et al.(1999, 2001).

\section{Plastic anisotropy and asymmetry modeling at high temperature}

From this section, we are going to concentrate on the modeling of inelastic phenomena for the Al-rich $\mathrm{Ti}-\mathrm{Al}$ alloys. As mentioned earlier, Al-rich TiAl alloys with nearly 62 at.\% $\mathrm{Al}$ are especially important due to the possibility of generating lamellar $\gamma$-TiAl $+r-\mathrm{Al}_{2} \mathrm{Ti}$ microstructures. So we choose a complex single crystal like alloy Ti-61.8at.\%Al with lamellar morphology and LPS. Based on the available experimental data, we will concentrate on the plastic anisotropy and asymmetry of this specific alloy at very high homologous temperature. With a proper physical framework, it is expected that micro-mechanical models can capture a wide range of experimentally observed macroscopic deformation phenomenon including the anisotropy and asymmetry. For highly rate dependent case, crystal viscoplasticity modeling is a good candidate to capture important deformation characteristics of different alloys including anisotropy as it is strongly orientation dependent (Ghosh and Anahid 2013; Roters et al. 2010). We will employ a crystal viscoplasticity modeling approach with slip system level isotropic and kinematic hardening variables to capture anisotropic and asymmetric effects. We believe the modeling approach with parameter identification technique can be extended to any other Al-rich alloys with long period superstructures. From here, the rest reviewing part is organized following the four recent works of Chowdhury et al. (2016, 2017a, b, c).

\section{Anisotropy in Ti-rich side}

Ti-rich lamellar alloys exhibit a significant plastic anisotropy whether they are polysynthetically twinned (PST) or polycrystalline intermetallics. Anisotropy of Ti-rich side alloys is highly pronounced irrespective of whether it is at room temperature (Werwer and Cornec 2006) or at high temperature (Wegmann et al. 2000). Room temperature plastic anisotropy of similar Ti-rich TiAl lamellar single crystals has also been discussed in Zambaldi et al. (2011), Zambaldi and Raabe (2010), and among others, where they showed that the maximum yield stress occurs when lamellar direction is perpendicular to the compression axis i.e $\phi=90^{\circ}$, stress is the minimum when approximately $\phi=45^{\circ}$, and at $\phi=0^{\circ}$ stress is in between (Brockman 2003, Fujiwara et al. 1990). The ratio of the highest to the lowest values of yield stress is almost 8:1. This large difference in yield stress has been found to be related to the difference in the deformation modes. For compression either perpendicular or parallel to the twin boundaries, shear deformation always occurs across them, while compression at an intermediate angle, shear deformation is parallel to the boundaries (Fujiwara et al. 1990). This means, deformation behavior depends strongly on the angle between the lamellar/twin boundary and compression axis rather than on the crystallographic orientation of the compression axis. So the plastic anisotropy of two-phase lamellar alloys or PST crystal is mainly a morphological anisotropy. This kind 
of anisotropy of TiAl single crystals is associated with the difference in the deformation mode e.g. shear deformation modes are different depending on $\phi$. Anisotropy is coming from to the asymmetric core spreading of the $<101$ ] superdislocations that occur in the $\mathrm{L} 1_{0}$ structure of $\gamma$-TiAl. The coupling of partial dislocations by different planar faults (that are specific for the $\mathrm{L} 1_{0}$ structure) makes the resistance to slip and cross slip of the $<101$ ] superdislocation sensitive to its direction of motion.

\section{Basic microstructural features of Ti-61.8at.\%Al}

As discussed earlier, after heat treatment at $950{ }^{\circ} \mathrm{C}$ for $200 \mathrm{~h} \mathrm{Ti}-62$ at.\%Al showed a fully lamellar microstructure of $\gamma-\mathrm{TiAl}+r-\mathrm{Al}_{2} \mathrm{Ti}$ where supersaturation with $\mathrm{Al}$ is apparently a prerequisite for the formation of such lamellar structure. With the same heat treatment parameters, the as-cast alloy with $62 \%$ at. Al contains some metastable phases, for example, numerous $h-\mathrm{Al}_{2} \mathrm{Ti}$ and spot of $\mathrm{Al}_{5} \mathrm{Ti}_{3}$ in some areas. Since $\mathrm{Al}_{5} \mathrm{Ti}_{3}$ is unstable after $800{ }^{\circ} \mathrm{C}$, some spots of this phase disappear after short time annealing and others transforms into $\gamma$. On the other hand $h-\mathrm{Al}_{2} \mathrm{Ti}$ transforms (probably by discontinuous dissolution) into equilibrium $r$-phase after similar heat treatment $950{ }^{\circ} \mathrm{C} / 200 \mathrm{~h}$ (Zhang et al. 2001). Nevertheless, it is a general agreement that $r$-phase will only display the structure of six fold face centered structure of $\mathrm{TiAl}_{2}$ at around $1000{ }^{\circ} \mathrm{C}$ (Lei et al. 2001). Since the working temperature is $1050{ }^{\circ} \mathrm{C}$, according to Sturm (2010), this specific alloy with nearly 62at.\%Al contains nearly lamellar stable phases of $\gamma$-TiAl $+r-\mathrm{Al}_{2} \mathrm{Ti}$. Al-rich single crystalline Ti61.8at.\% Al is an intermetallic binary alloy with lamellar phases of $\gamma$-TiAl and $r-\mathrm{Al}_{2} \mathrm{Ti}$ superstructure. Heat treatment parameters are $950 \% 200 \mathrm{~h}$ and WQ(water quenching), from which single crystal like samples have been produced using laser zone melting process. The chemical analysis of this alloy is presented in Table 1.

As mentioned earlier, the $\gamma$-phase has face centered crystal structure and the $r$-phase has so called ordered superstructure that contains 6 face centered structures together as shown in Fig. 4. Volume fraction $(\gamma / r)$ in the lamellar state is nearly 1.1:1, Fig. 5. The volume fraction of $r$ phase depends on the annealing temperature and decreases with the increase of temperature. A summary of $\mathrm{Ti}-62.5 \% \mathrm{Al}$ on the volume fraction with different annealing temperature can be found in (Nakano et al. 2002b). Microstructural investigation in Ti61.8at.\% $\mathrm{Al}$ shows that, in most regions, the average width

Table 1 Compositions of different elements in Ti-61.8at.\%Al alloy \begin{tabular}{lllllll}
\hline $\mathrm{Ti}$ & $\mathrm{Al}$ & $\mathrm{Fe}$ & $\mathrm{C}$ & $\mathrm{H}$ & $\mathrm{O}$ & $\mathrm{N}$ \\
\hline 37.0 at.\% & 61.8 at.\% & $238 \mathrm{ppm}$ & $69 \mathrm{ppm}$ & $206 \mathrm{ppm}$ & $608 \mathrm{ppm}$ & $125 \mathrm{ppm}$
\end{tabular}

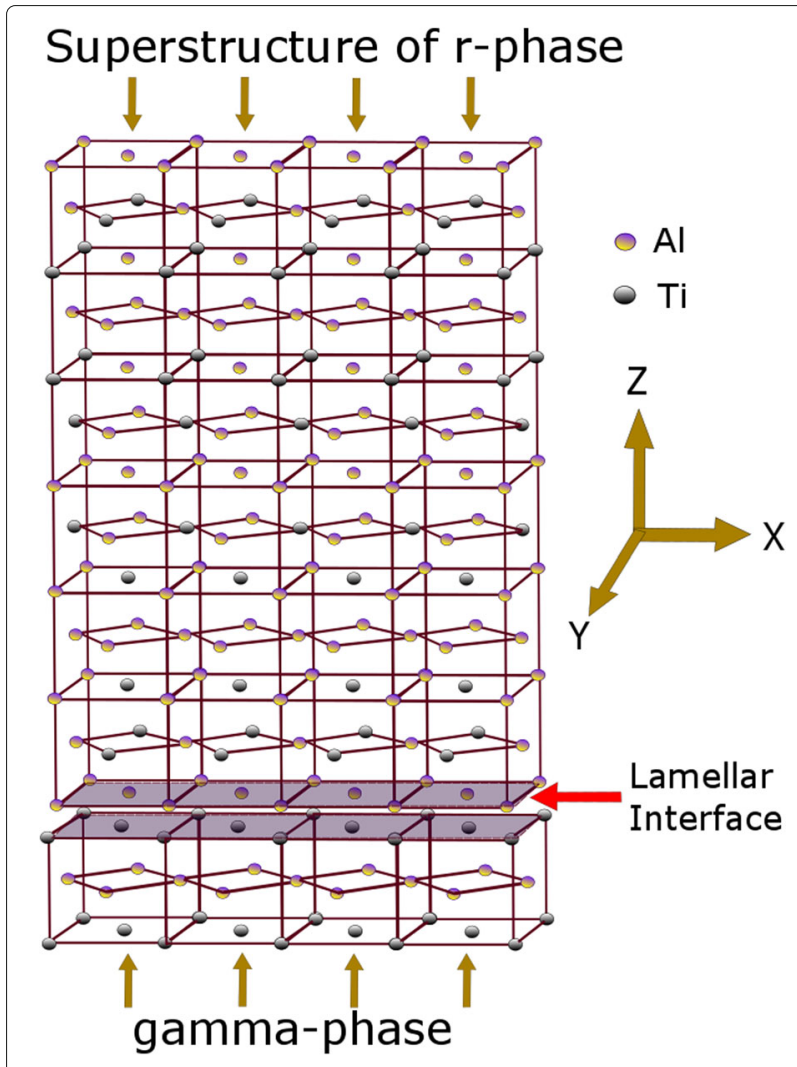

Fig. 4 Crystal structures of $\gamma$-TiAl with $L 1_{0}$ structure (down), $r-\mathrm{TiAl}_{2}$ with ordered superstructure with schematic periodic arrangement (up), and interface in between, for Ti-61.8at.\%Al

of a $r-\mathrm{Al}_{2} \mathrm{Ti}$ precipitate is about $0.6 \pm 0.2 \mu \mathrm{m}$ while the inter-lamellar spacing is mostly about $1 \pm 0.5 \mu \mathrm{m}$.

Annealed below $1200{ }^{\circ} \mathrm{C}$, this alloy maintains the orientation relationship (OR): $[001]_{\gamma} \|[001]_{\mathrm{r}}$ and $\left.<100\right]_{\gamma}$ $\|<100]_{\mathrm{r}}$. At the lamellar boundary, interface planes

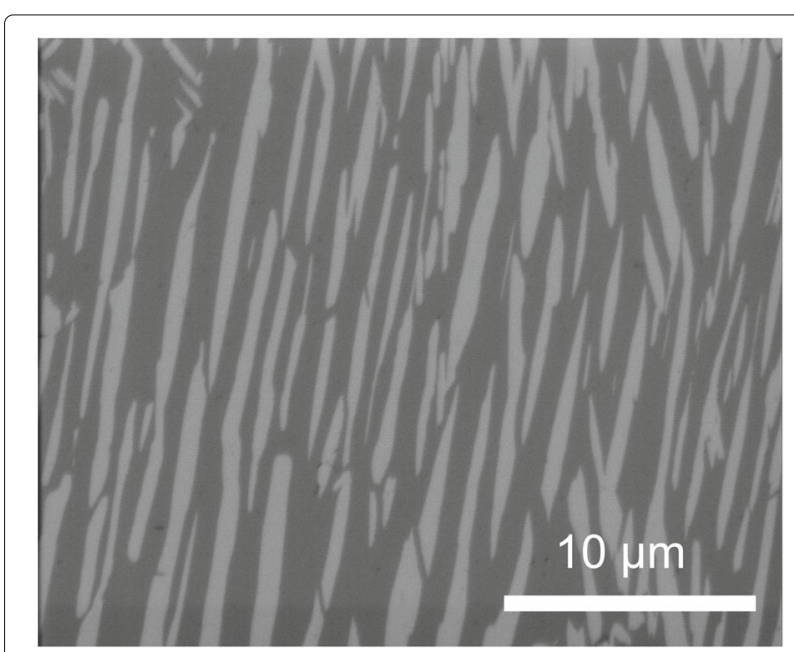

Fig. 5 Microscopic imaging of nearly lamellar and single crystal like alloy Ti-61.8at.\%Al (Sturm 2010), as evaluated by FIB (Focused Ion Beam) imaging, $r$-plates: bright and $\gamma$-phase: dark 
are parallel, e.g. the $\gamma / r$ interfaces are basically formed by the (001) planes of both phases (Stein et al. 2001) maintaining $(001)_{\gamma} \|(001)_{\mathrm{r}}$. We find the similar orientation relationship in Ti- $62.5 \% \mathrm{Al}$ alloy between $\mathrm{Al}_{5} \mathrm{Ti}_{3}$ and $r$ phases (Lei et al. 2000). Observations also show that the OR is independent of annealing procedures and can approximately be regarded as cubic-to-cubic relationship (Lei et al. 2001; Sturm 2010). Like Ti-rich side, $\gamma$-matrix phase is comparatively softer at room temperature. Furthermore, the investigation revealed that dislocations are not only in the $\gamma$-phase, but regular misfit dislocations are at the $\gamma / r$ inter lamellar boundary interfaces (Sturm et al. 2010), resulting significant slips on (001) planes above the peak temperature of $800{ }^{\circ} \mathrm{C}$ (Hayashi et al. 2001; Nakano et al. 2002b) with two types of $1 / 2<110$ ] dislocations. Line direction of the two types of dislocations are $1 / 2[110]$ and $1 / 2[1 \overline{1} 0]$, so both type of dislocations are near-edge dislocations in the (001) interface plane and interfacial misfit of approximately $0.6 \%$ may exist between $\gamma / r$ in (001) plane (Zhang et al. 2001). Due to the ordered superstructure one would expect that the translation vectors (Burgers vectors) are very large in the $r$-phase. Thus, dislocation glide or climb could be confined to the $\gamma$-phase for specific loading responses.

As mentioned earlier, $\left.\{111\} \frac{1}{2}<110\right]$ slip was dominant at temperatures below the peak, while there are some reports stating that slip predominance changes to (001) plane above the peak temperature. Similar behavior is also observed in Ti-62.5at.\%Al and Ti-58.0at.\%Al. Slight slip traces on (001) were observed in Ti-62.5at.\%A1 even below the peak temperature. The dislocations in the $r$ $\mathrm{Al}_{2} \mathrm{Ti}$ precipitate are aligned on a straight line parallel to $\frac{1}{2}[110]$ with a screw character (Nakano et al. 1998). It should be noted that in the case of large scale glide, even at high temperatures, slip planes $\{111\}$ are significant (Appel et al. 2011). Analyzing deformation mechanisms of similar Al-rich lamellar alloys (Ti-61.8at.\%Al, Ti-62at.\%Al and Ti62.5at.\% Al) both the families, e.g. $\{111\}$ and (001), can be considered to be active at elevated temperature. This alloy does not contain any superstructure other than $r-\mathrm{Al}_{2} \mathrm{Ti}$ and there is no experimental evidence that $\{110\}$ planes are active for this specific material above the peak temperature. Since superdislocation slips are kinematically necessary and sometimes they are experimentally observed for similar alloys, here all twelve systems from the octahedral family can be considered. To account lamellar interface effects, slip planes perpendicular to the interface are also important, so all six systems from the cubic family will also be considered. In total, 18 slip systems from the both families have been considered. Besides in a rate dependent formulation, all slip systems potentially can be active for stress above the threshold even though only a few slip systems accommodate most of the deformation (Asaro and Needleman 1985; Mathur and Dawson 1989; Zhang et al. 2007). After all, considering few non active systems in rate dependent case does not make a significant change in the results.

\section{Glide-climb driven hardening/recovery and experimental data}

At high temperature, evolving mechanical properties of metallic materials are not simply dependent on dislocation glide mechanisms. There are climb-assisted deformations and creep as well, which are known to contribute significantly. Climb is a diffusion-controlled (thermal activated) process and occurs more readily at elevated temperature where dislocations will more easily be able to move around the obstacles. Many hardened materials, for this reason, become exponentially weaker at higher temperatures. Generally climb reduces the plastic incompatibility between two phases (for two and multiphase alloys), which is certainly beneficial for the materials plasticity. So two constituents can deform more easily at elevated temperature. The recovery is an important restoration/repair mechanism against work hardening, that is inescapable at high temperature. The most believed mechanism of recovery is the mutual dislocation annihilation in planarglide which is thermally activated and facilitated by climb stresses. Along with climb of groups of dislocations, it is also caused by large-scale cross slips leading to a continuous decrease of the work hardening rate. If the temperature is increased enough for climb, dislocations will rearrange and/or annihilate so as to reduce the stored energy. It entails a gradual decrease in the number of dislocations and a rearrangement of the remaining ones into orderly arrays. In other words, some of the dislocations are annihilated, others are gathered into stable, planar favorable configurations. The recovery may occur by climb for edges or cross slip for screws. The screw dipoles can be removed by cross slip and the edge dipoles by climb. At high temperature, the kinetics of deformation are highly temperature and rate-dependent and the internal structure of a metal evolves, producing strain-hardening, dynamic recovery, and in many instances dynamic recrystallization (Brown et al. 1989).

Particularly in our case of Ti-61.8at.\%Al alloys at $1050^{\circ} \mathrm{C}$, not only deformation of the $\gamma$ phase is supported by climb of ordinary dislocations but also these factors make the codeformation of the two phases easier and ensure strain continuity (Appel et al. 2011). The strength difference between the two phases which is significant at room temperature becomes less at that high temperature. For Ti-52at.\%Al alloys, it has been suggested that at slower strain rates (e.g. between $10^{-3} \mathrm{~s}^{-1}$ and $10^{-5} \mathrm{~s}^{-1}$ ), the deformation mechanism involves both glide and climb; glide occurs initially and generates a dislocation substructure with the appropriate link length for climb. 
So it is clear that climb of dislocations plays a significant role in the plastic deformation of TiAl at elevated temperatures. The motion of dislocations $1 / 2<110$ ] is achieved by either or both glide and climb, the degree to which these various mechanisms contribute depending on the temperature and strain rate. Thus, at $900{ }^{\circ} \mathrm{C}$ and strain rates less than approximately $10^{-2} \mathrm{~s}^{-1}$, climb is found to contribute rather significantly to the plastic deformation (Nakano et al. 1998). If we look at the experimental data (true stress vs true strain in Fig. 6) we can see there is strain hardening and there is significant recovery of hardening in the next stage due to climb assisted deformation with possible other softening effects.

From Fig. 6, we can see that the $\phi=0^{\circ}$ lamellar orientation with the compression axis exhibits higher stress than that of $\phi=90^{\circ}$, which is in contrast with Ti-rich intermetallic of PST (polysynthetically twinned) crystals.

\section{Basic assumptions}

The intermetallic Ti-61.8\%at.Al alloy is a complex material with lamellar morphology and long period superstructures. Depending on the orientation and temperature, both microstructural and morphological features ensure alloy strengthening by suppressing dislocation movement resulting higher CRSS of some slip systems. With slip-system-level necessary internal variables and glideclimb driven constitutive equations, it is assumed that the crystal viscoplasticity model is well capable to capture experimentally observed macroscopic deformation phenomenon when critical stresses are designed properly. Instead of considering directional dependent CRSS for an individual system, a fixed value for anisotropic responses has been considered to reduce the number of unknown parameters. Since the orientation relationship of two phases is similar, so it can be assumed that CRSS

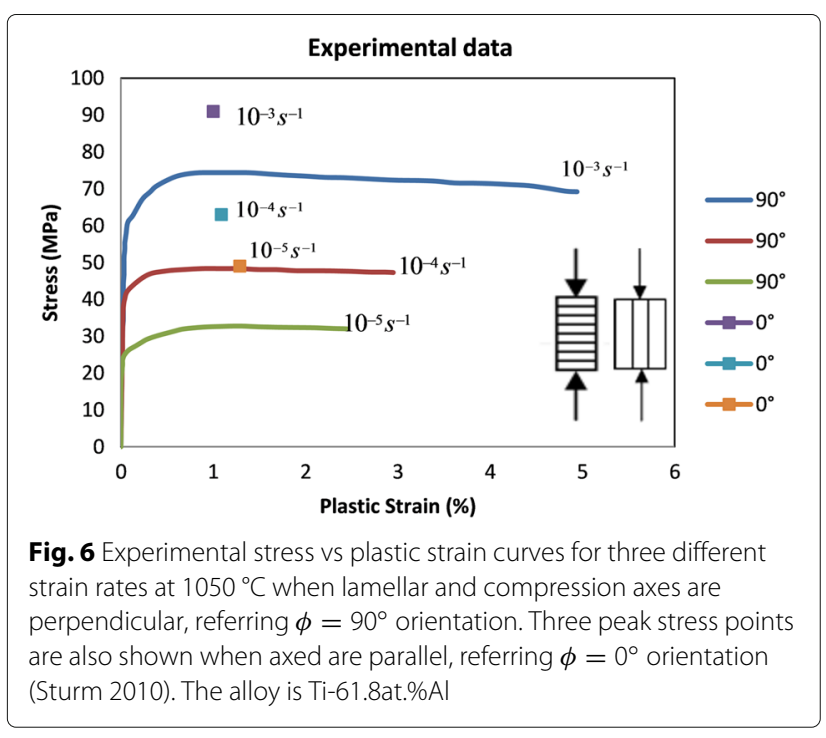

for an individual system would be overall instead of different. Besides, the actual differences of CRSS between two phases at operating temperature is not known. Although the microstructure is not perfectly lamellar, according to mean field approach, representative volume element (RVE) is idealized with perfectly lamellar and with different lamellar thicknesses, Fig. 7. Since the microstructure is non-periodic, it is preferred to consider sufficiently large RVE (thirteen lamellae). Figure 7 shows the RVE when loaded perpendicular to the lamellae. The RVE is meshed with 16250 eight node solid elements C3D8 from the Abaqus element library. Loading and boundary surfaces are also shown. Generally the objective of studying single crystals is to understand grain level mechanics of polycrystalline alloys. Since Ti-61.8at.\%Al is a single crystal alloy, two basic aspects of mean field homogenization have been simplified. Firstly, three different strain rates (i.e. $10^{-3} \mathrm{~s}^{-1}, 10^{-4} \mathrm{~s}^{-1}$ and $10^{-5} \mathrm{~s}^{-1}$ ) perpendicular to the one side of the Z-planes have been applied, and displacement boundary condition has been applied to the opposite side i.e. $U_{3}=0$, as shown in Fig. 7. No restriction has been applied to the other four sides of the RVE. Secondly, overall stress has been computed based on the element centroidal average of the stress component $\sigma_{33}$. In the computing of overall stress, a significant difference between the volumetric average and centroidal average is not expected, since the volumes of different elements are nearly the same. Elastic components were considered different for two phases.

\section{Continuum framework}

In this section we will summarize continuum framework based on finite strain and finite rotation. It is well known that the geometric basis of the continuum slip theory is a multiplicative decomposition of the deformation gradient

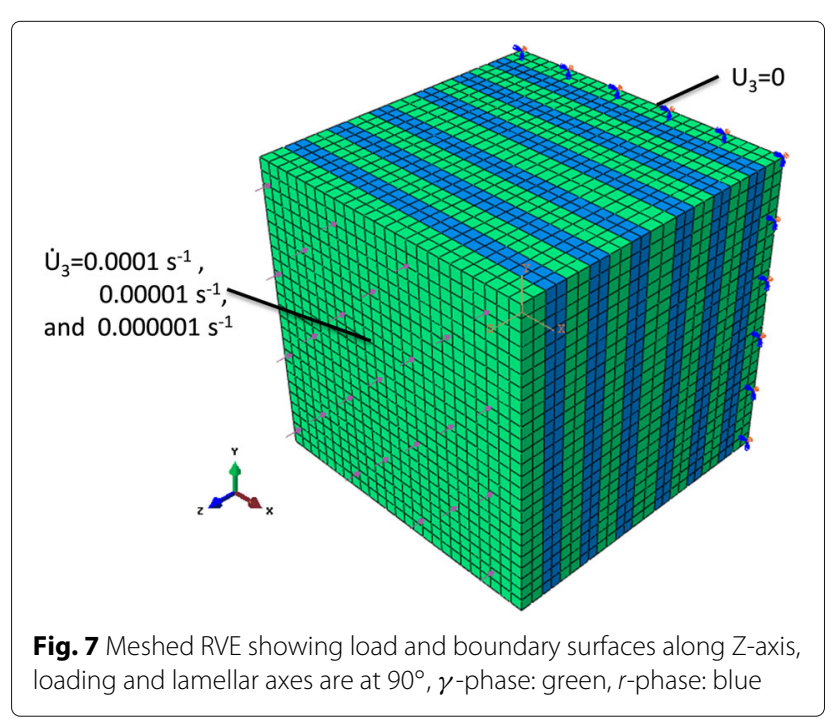


(F) into a plastic part, solely due to crystalline slip on given crystallographic planes $\left(\boldsymbol{F}^{p}\right)$, and a remaining part $\left(\boldsymbol{F}^{*}\right)$, say elastic part, that describes elastic distortions of the lattice and rigid rotations (Conti and Hackl 2015). Based on the isoclinic assumption, the plastic deformation is assumed here to take place first, followed by the elastic one. Elastic distortion as well as rigid-body rotations (lattice rotation) are both contained in $\boldsymbol{F}^{*}$ which maps the intermediate configuration to the current configuration. The velocity gradient follows the standard expression as:

$$
\begin{aligned}
\boldsymbol{L} & =\dot{\boldsymbol{F}}^{*} \cdot \boldsymbol{F}^{*-1}+\boldsymbol{F}^{*} \cdot\left(\dot{\boldsymbol{F}}^{p} \cdot \boldsymbol{F}^{p-1}\right) \cdot \boldsymbol{F}^{*-1} \\
& =\dot{\boldsymbol{F}}^{*} \cdot \boldsymbol{F}^{*-1}+\sum_{\alpha=1}^{N} \dot{\gamma}^{\alpha}\left(\mathrm{s}^{\alpha} \otimes \mathrm{m}^{\alpha}\right)
\end{aligned}
$$

where $\dot{\gamma}^{\alpha}$ is the slipping rate along the slip system $\alpha, N$ is the total number of slip systems, and the vectors $\boldsymbol{s}^{\alpha}$ and $\mathbf{m}^{\alpha}$ define the slip direction and the normal to the slip plane in the deformed configuration, respectively. It is to be noted that $\mathbf{s}^{\alpha}$ and $\mathbf{m}^{\alpha}$ are not necessarily the unit vectors, but at the initial configuration, $\mathbf{s}_{0}^{\alpha}$ and $\mathbf{m}_{0}^{\alpha}$, they are unit and orthogonal. So it is obvious that $\mathbf{s}^{\alpha}=\boldsymbol{F}^{*} \cdot \mathbf{s}_{0}^{\alpha}$. To maintain orthogonality in the deformed state it is necessary to define $\mathbf{m}^{\alpha}=\mathbf{m}_{0}^{\alpha} \cdot \boldsymbol{F}^{*-1}$ so that $\mathbf{m}_{0}^{\alpha} \cdot \mathbf{s}_{0}^{\alpha}=$ $\mathbf{m}^{\alpha} \cdot \mathbf{s}^{\alpha}=0$. The resolved shear stress $\tau^{\alpha}$ is defined in terms of Kirchhoff stress $\boldsymbol{\tau}$ as follows:

$$
\begin{aligned}
\tau^{\alpha} & =\mathbf{s}^{\alpha} \cdot \boldsymbol{\tau} \cdot \mathbf{m}^{\alpha}=\mathbf{m}^{\alpha} \cdot \boldsymbol{\tau} \cdot \mathbf{s}^{\alpha}=\mathbf{m}^{\alpha} \cdot J \boldsymbol{\sigma} \cdot \mathbf{s}^{\alpha} \\
& =\operatorname{sym}\left(\mathbf{s}^{\alpha} \otimes \mathrm{m}^{\alpha}\right): J \boldsymbol{\sigma} \\
& =\boldsymbol{\mu}^{\alpha}: J \boldsymbol{\sigma}=\boldsymbol{\tau}: \boldsymbol{\mu}^{\alpha}
\end{aligned}
$$

For small elastic strains, it is to be noted that volumetric change resulting from elastic stretch of crystal is usually very small. Therefore, the assumption that $J \approx 1$ is generally justified and no distinction between the Kirchhoff and Cauchy stresses is needed in practical or engineering computations (Kuroda 2014). So for small strains formulation it is often taken as $\tau^{\alpha}=\sigma: \mu^{\alpha}$ (Meric et al. 1991).

\section{Crystal viscoplasticity constitutive modeling}

In this alloy, following Meric et al. (1991), the viscoplastic driving force for a slip system has been taken as the difference of shear stress and all hardening stresses given in the flow rule, Eq. (3).

$$
\dot{\gamma}^{\alpha}=\left\langle\frac{\left|\tau^{\alpha}-X^{\alpha}\right|-R^{\alpha}}{K}\right\rangle^{n} \operatorname{sgn}\left(\tau^{\alpha}-X^{\alpha}\right)
$$

Here $\dot{\gamma}^{\alpha}$ is the shear rate of the slip system $\alpha$, similarly $\tau^{\alpha}$ is the shear stress, $X^{\alpha}$ is the backstress and $R^{\alpha}$ is the threshold stress, a component of friction that evolves with slip, of the same slip system. $K$ is temperature dependent drag stress. $X$ and $R$ are the two phenomenological internal state variables for internal stress and internal resistance where $R$ can be considered for the critical resolved shear stress (CRSS) evolution. Inclusion of backstress in the model by strain hardening and dynamic recovery is simple and physically sound (Ohno and Wang 1993). Moreover, it allows us to distinguish a tensile and a compressive yield strength. This flow rule should be considered as an extension to the micro-level of macroscopic model including isotropic and nonlinear kinematic hardening (Meric et al. 1991). In the power law flow rule, Eq. (3), $K$ and $n$ are two material coefficients characterizing the viscous effect of a hardened material. Macaulay brackets $<y>$ indicate the following:

$$
<y>=\left\{\begin{array}{l}
y, y \geq 0 \\
0, y<0
\end{array}\right.
$$

The isotropic hardening variable is defined as follows:

$$
\begin{aligned}
& R^{\alpha}=R_{0}^{\alpha}+\sum_{\beta} \mathbf{H}^{\alpha \beta}\left(1+b^{\beta}\right) q^{\beta} \\
& \dot{q}^{\alpha}=\left|\dot{\gamma}^{\alpha}\right|\left(1-b^{\alpha} q^{\alpha}\right)
\end{aligned}
$$

From any slip system, $R$ starts with initial CRSS $R_{0}$ and its evolution is governed by the variable $q$ along with the choice of recovery parameters $b$ and hardening interaction (cross hardening) matrix $\mathbf{H}^{\alpha \beta}$. If $b=0$ then there would be no recovery or any other softening effect. Along with the governing isotropic state variable $q$, the variable $R$ represents isotropic hardening or softening effects. In the interaction matrix $\mathbf{H}^{\alpha \beta}$, diagonal components are 1 and off-diagonal components depend on the material behavior. First term in the right side of Eq. (6) is for strain hardening effect and second one can be considered for dynamic recovery or related softening. Backstress evolution is represented in the following equations:

$$
\begin{aligned}
X^{\alpha} & =C^{\alpha} a^{\alpha} \\
\dot{a}^{\alpha} & =\phi\left(v^{\alpha}\right) \dot{\gamma}^{\alpha}-\left|\dot{\gamma}^{\alpha}\right| d^{\alpha} a^{\alpha} \\
\phi\left(v^{\alpha}\right) & =\phi_{0}+\left(1-\phi_{0}\right) e^{-\delta v^{\alpha}}
\end{aligned}
$$

$C$ is here the temperature dependent internal stress of the slip system $\alpha$ and $a$ is responsible for kinematic hardening evolution which depends on the shear rate and the deformation history function $\phi\left(v^{\alpha}\right)$. Here $v^{\alpha}$ is the cumulative shear strain of the slip system $\alpha$.

$$
v^{\alpha}=\int_{0}^{t}\left|\dot{\gamma}^{\alpha}\right| \mathrm{d} t
$$

Activation of a slip system depends not only on the orientation but also on the deformation history, which contributes to the hardening (Khadyko et al. 2016). This function is responsible for deformation history effects and it depends on the plastic flow accumulation $v^{\alpha}$ with two related material parameters $\phi_{0}$ and $\delta$ as given in Eq. (9). Like isotropic hardening variable, the first term in the right side of Eq. (8) represents strain hardening and the second part stands for dynamic recovery effects. 
This coupling function $\phi\left(v^{\alpha}\right)$ helps to avoid under or overestimation of the strain hardening part. For detailed numerical implementation technique, Chowdhury et al. (2017b) can be referred. Generating a lamellar representative volume element (RVE) with $10 \times 10 \times 10 \mu \mathrm{m}^{3}$, Fig. 7, all the necessary incremental formulas have been implemented in the UMAT (user material) subroutine from the commercial finite element software package ABAQUS Standard.

\section{Components of the elasticity tensor}

Elastic constants of $\gamma$ and $r$-phases have been approximated at $1050^{\circ} \mathrm{C}$ following $\mathrm{He}$ et al. (1997); Tanaka (1996); Tang et al. (2011); Yoo and $\mathrm{Fu}$ (1998), Table 2. For this alloy, $C_{11}=C_{22}, C_{23}=C_{13}$, and $C_{55}=C_{44}$. So there will be only six independent components.

\section{Results and discussions}

\section{Plastic Anisotropy of Ti-61.8at.\%Al single crystals}

Considering the framework discussed earlier along with a fixed set of materials and model parameters, the rate dependent plastic anisotropic behaviors (Fig. 6) can be successfully simulated both at $\phi=90^{\circ}$ and $\phi=0^{\circ}$ orientations. Simulation results are illustrated in Figs. 8 and 9. For this specific case of partial lamellar morphology, it seems Hall-Patch stress is the dominating factor of plastic anisotropy. In contrast to Ti-rich alloys, the overall stress responses are higher at $\phi=0^{\circ}$ than that of at $\phi=90^{\circ}$. This is because, some dislocations can easily pass across the gap of two discontinuous $r$-lamellae at $\phi=90^{\circ}$, which is comparatively difficult at $\phi=0^{\circ}$ loading orientation. From the crystal plasticity constitutive modeling perspective, it is observed that the overall plastic behavior in the first stage is dominated by the kinematic hardening part while the both isotropic and kinematic hardening governs the next stage (Chowdhury et al. 2017b). So one can say the plastic deformation behavior of off-stoichiometric Al-rich TiAl alloys generally depends strongly on the morphology, size and condition of the superstructures (Hata et al. 2004a; Nakano et al. 2002a).

\section{Material and model parameters}

Rate sensitivity parameter $n$ is expected to be in the range of 3 to 6 , preferably 5 or lower at intermediate stress and high temperature. As claimed by Kassner and PerezPrado (2000), if the deformation mechanism is associated with dislocation climb then the exponent is relatively 5

Table 2 Extrapolated elastic stiffness constants (in GPa) of $\gamma$ and $r$ phases at $1050^{\circ} \mathrm{C}$

\begin{tabular}{lllllll}
\hline Phase & $C_{11}$ & $C_{12}$ & $C_{23}$ & $C_{33}$ & $C_{44}$ & $C_{66}$ \\
\hline$r$-TiAl & 150 & 76 & 76 & 153 & 82 & 64 \\
$r$-TiAl 2 & 162 & 73 & 60 & 182 & 60 & 80 \\
\hline
\end{tabular}

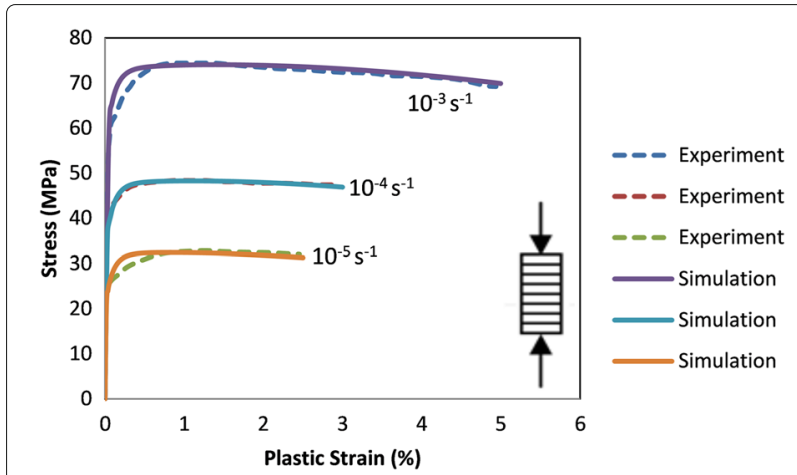

Fig. 8 Rate dependent plasticity of Ti-61.8at.\%Al alloy, when the lamellar and loading axes are at $90^{\circ}$ : experiment vs. simulation with the proposed approach

over a range of temperature and strain rates as long as temperature is greater than roughly $0.5-0.6$ of melting temperature. The rate sensitivity parameter is found $n$ as 4.5 which seems very reasonable considering temperature and stress range. Other parameters are shown in Table 3.

\section{CRSS Estimation}

CRSS in Ti-rich TiAl Shear deformation parallel to the lamellar interfaces is considered to be easier (the soft mode) than that normal to the interfaces (the hard mode) (Grujicic and Batchu 2001). The relative difficulty of these harder slip modes compared to the softer ones plays an important role in determining textures, strength and ductility (Hutchinson and Barnett 2010). Considering Ti-rich TiAl, Grujicic and Batchu (2001) proposed half of the slip systems belongs to the softer group and half to the harder group based on interface effect. Lebensohn et al. (1998) extended this harder-softer version to more elegant morphology based characterization. The idea of this approach is, there are few planes and directions that are parallel to

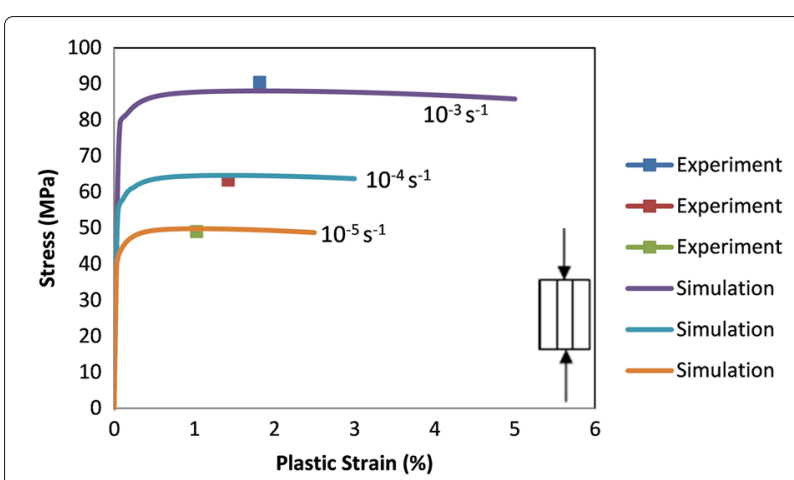

Fig. 9 Rate dependent plasticity of Ti-61.8at.\%Al alloy, when the lamellar and loading axes are at $0^{\circ}$ : experiment vs. simulation with the proposed approach 
Table 3 Model parameters for the plastic anisotropy and asymmetry of Ti-61.8at.\%Al alloy

\begin{tabular}{lll}
\hline Parameters & Name & Values \\
\hline Rate dependence & Rate sensitivity, $n$ & 4.5 \\
& Drag stress, $K(\mathrm{MPa})$ & 122 \\
Isotropic hardening & initial CRSS, $R_{0}(\mathrm{MPa})$ & 14 \\
& recovery parameter, $b$ & 9 \\
Kinematic hardening & internal stress, C(MPa) & 3500 \\
& recovery parameter, $d$ & 45 \\
& parameters for flow accumulation & 0.24 \\
& function, $\phi_{0}$ and $\delta$ & and 600 \\
\hline
\end{tabular}

the lamellar interface while some are (nearly) transverse, and rest are mixed. When the lamellae are at $\phi=90^{\circ}$ with the loading axis, the deformation is carried out mainly by systems of the transverse type which should have high critical stresses while parallel systems should have low CRSS and mixed type systems are expected to be in between. This means, $R_{0}^{\mathrm{T}}<R_{0}^{\mathrm{M}}<R_{0}^{\mathrm{L}}$, where $R_{0}$ denotes CRSS and superscripts $L, M, T$ stand for longitudinal, mixed and transverse systems. This morphology-based or phase interface based classification has been successfully applied to many other applications e.g. colony boundary strengthening of fully lamellar TiAl alloys (Schnabel and Bargmann 2017).

CRSS for Al-rich TiAl There is a number of experimental works that have been performed on $\gamma$-TiAl single crystals, most of them with an aluminum concentration of $54 \%$ or $56 \%$. In two-phase lamellar alloys, the estimation of the CRSS of $\gamma$-phase is complicated by the lamellar morphology (Werwer and Cornec 2006). Nevertheless, the general agreement is that, crystals containing $\mathrm{L}_{0}$ phase beyond 54at.\%Al, the CRSS for $\left.1 / 2<110\right]\{111\}$ ordinary slip is higher than that for $<101]\{111\}$ superlattice slips up to some peak temperature level (Inui et al. 2002; Nakano et al. 2005). An increase in Al concentration hardened the TiAl and the difference increases suggesting that ordinary dislocations become relatively less mobile than <101] dislocations (Inui et al. 1997, 2002; Nakano et al. 1996, 2005). Nakano et al. (2005) made the similar conclusion after investigating alloys with different compositions e.g. Ti-54.7at.\%Al,Ti-56.0at.\%Al, Ti-58.0at.\%Al, Ti-60.0at.\%Al and Ti-62.5at.\%Al annealed at $1200{ }^{\circ} \mathrm{C}$. So below the peak temperature, superlattice dislocations control the plastic behavior of Al-rich TiAl (Nakano et al. 1996). Since the energy of the antiphase boundary created by the ordinary dislocations was higher than that created by the superlattice dislocations, the motion of the ordinary dislocations was effectively interrupted by the APBs, resulting the activation of the superlattice dislocations, and a loss of ductility in Al-rich
TiAl. The formation of superstructures in the $\mathrm{L} 1_{0}$ matrix was responsible for the change in deformation modes and low ductility in Al-rich TiAl (Nakano et al. 1996). The difference in CRSS between these two slip systems (ordinary and super) become pronounced with the development of the $\mathrm{Al}_{5} \mathrm{Ti}_{3}$ long-period superstructure. The frequency of $<101$ ] dislocation decomposition into a $1 / 2<110$ ] and a $1 / 2<112$ ] dislocation decreases abruptly with the development of $\mathrm{Al}_{5} \mathrm{Ti}_{3}$. A reduced mobility of ordinary dislocations may be at the origin of this behavior (Nakano et al. 2005). Nakano et al. (2002a) showed that, at $500{ }^{\circ} \mathrm{C}$, the CRSS of $\{111\}<101]$ increases linearly with increasing $\mathrm{Al}$ concentration, while the CRSS of $\{111\} 1 / 2<110]$ was lower at the beginning then increases rapidly till 58at.\% then starts falling sharply and goes below the line of superdislocation slip. Inui et al. (1997) and Nakano et al. (1996) further reported that, at temperatures below $600{ }^{\circ} \mathrm{C}$, the CRSS for $1 / 2<110$ ] ordinary slip is considerably higher than hat of $<101]$ superlattice slip. The ratio of the CRSS is 1.5-2.0 at room temperature. However, after $900{ }^{\circ} \mathrm{C}$ the trend reverse, approx after $1050{ }^{\circ} \mathrm{C}$ superslips are no longer active in $\mathrm{Ti}-56 \%$ at. Al (Inui et al. 1997). A contradictory case also can be seen in Gregori and Veyssiere (2000), where they proposed, it is reasonable to assess that $<011]\{111\}$ and $1 / 2<112]\{111\}$ exhibit the smallest and highest CRSSs, respectively, with that of $1 / 2<110]\{111\}$ located in between. It is worth to mention that, at $\mathrm{T}>900{ }^{\circ} \mathrm{C}$, orientation dependence of CRSS and difference among ordinary systems becomes very less (Feng and Whang 1999, 2000). Interestingly, the CRSS value is found to be independent of deformation orientation below room temperature at $-77^{\circ} \mathrm{C}$, while a strong orientation dependence of the CRSS values is clearly observed for all different orientations between $400{ }^{\circ} \mathrm{C}$ and $800{ }^{\circ} \mathrm{C}$ (Feng and Whang 2000).

CRSS estimation for Ti-61.8at.\%Al As mentioned earlier, increase in $\mathrm{Al}$ concentration makes TiAl harder with the appearance of superstructures. It is expected that $r$ phase with LPS dictates the overall deformation process at least for some orientations. But how and which systems are directly affected by the LPS is not clearly understood. From the two experimental data sets of Fig. 6, we see that the $\phi=0^{\circ}$ orientation is harder than that of $\phi=90^{\circ}$ for all strain rates, which implies that slip along some slip systems are directly suppressed by the LPS in the former case. Besides $r$-lamellae are discontinuous, slip can occur across the gap at $\phi=90^{\circ}$ loading orientation which makes the deformation process softer. Deformation is carried out by the softer $\gamma$-phase, where LPS contributes to alloy strengthening. On the other hand at $\phi=0^{\circ}$ orientation, the harder $r$-phase absorbs external loading first, then it is transmitted to softer phase as well. The transmission of dislocations through the interface is harder at 
$\phi=0^{\circ}$ loading. It is agreed that, below the peak temperature, motions of the ordinary type dislocations are suppressed by LPS resulting additional resistance (Inui et al. 2002; Nakano et al. 2005; Umakoshi et al. 1999). So, at $\phi=0^{\circ}$ lamellar orientation, it is assuming that some ordinary systems remain harder at high temperature as well due to the LPS. To identify those unique systems and to estimate CRSS, an operative stress based approach has been adopted for a particular loading response. Usually some slip systems are favored for one orientation while other systems are favored for another orientation, which is showed by Inui et al. (1997); Nakano et al. (1996) and the most dominant system in a particular loading direction controls the major part of the plastic deformation. According to the presented crystal plasticity constitutive modeling, a slip system is considered to be active when the operative stress $|\tau-X|-R$ on that system is positive. Based on this, individual overall operative stress of all slip systems has been computed both at $\phi=0^{\circ}$ and $\phi=90^{\circ}$ orientations. Since all superslips have higher CRSS than ordinary group, it can be assumed that the reason of underestimating experimental data at $\phi=0^{\circ}$ is that the CRSS of some ordinary systems are underestimated. That is why, it is assumed that those unique systems lie in the ordinary group where CRSS is underestimated. Shear along those dominating systems are expected to control the plastic deformation at $\phi=0^{\circ}$. After analyzing operative stresses for all slip systems it is found that the major contributing ordinary slip systems are (1111) $\frac{1}{2}[110]$, (001) $\frac{1}{2}[110]$ and (001) $\frac{1}{2}[1 \overline{1} 0]$. To be consistent with the available experimental observations, all twelve superslip systems from the both family have been considered with the highest CRSS, and three ordinary systems with the lowest CRSS and rest three harder ordinary systems are in between, i.e. $R_{0}^{\mathrm{O}}<R_{0}^{\mathrm{HO}}<R_{0}^{\mathrm{S}}$. Here subscripts $\mathrm{O}$, HO and $\mathrm{S}$ for the ordinary, harder ordinary and superslip systems, respectively. To approximate a reasonable value of $R_{0}^{\mathrm{HO}}$ along a slip system $\alpha$, the following formula has been adopted:

$$
R_{0}^{\mathrm{D} \alpha}=\frac{R_{0}^{\mathrm{O}} \bar{\tau}_{\mathrm{T}}^{\alpha}+R_{0}^{\mathrm{S}} \bar{\tau}_{\mathrm{L}}^{\alpha}}{\bar{\tau}_{\mathrm{T}}^{\alpha}+\bar{\tau}_{\mathrm{L}}^{\alpha}}
$$

where $R_{0}^{\mathrm{O}}$ and $R_{0}^{\mathrm{S}}$ stand for the CRSS of ordinary and superlattice systems, respectively. $\bar{\tau}_{\mathrm{L}}^{\alpha}$ and $\bar{\tau}_{\mathrm{T}}^{\alpha}$ denote averaged operative shear stresses on the slip system $\alpha$ for the loading in longitudinal $\left(\phi=0^{\circ}\right)$ and transverse $\left(\phi=90^{\circ}\right)$ directions, respectively. In essence, these three harder ordinary systems took a weighted average value of CRSS based on both directional operative stresses. Since individual CRSS in different loading directions is not differentiated, a weighted averaged value is expected to be more meaningful, which is approximated by Eq. (11). For example, considering slip system $(001) \frac{1}{2}[1 \overline{1} 0]$, it is found,
$\bar{\tau}_{\mathrm{T}}=16.5 \mathrm{MPa}$ and $\bar{\tau}_{\mathrm{L}}=10.9 \mathrm{MPa}$. So approximate CRSS for this system would be $\frac{14 \times 16.5+24.5 \times 10.9}{16.5+10.9} \approx 18.2 \mathrm{MPa}$. Similarly, 23 and $24.5 \mathrm{MPa}$ for two other systems have been found. Further detail of the estimation procedure can be found in Chowdhury et al. (2017b). The full list of estimated CRSS are presented in Table 4. For better visibility in the tabular form, index $\overline{1}$ is written as -1 . From the table, it can be seen that CRSS ratio varies from 1.3 to 1.8 which is also consistent with the experimental finding.

In short, all ordinary systems are harder below the peak temperature, and all superlattice dislocation slips are harder beyond the peak. In this particular alloy, additionally three special ordinary systems with comparatively higher CRSS above the peak temperature have been attributed. The presence of LPS might be a potential reason, that can suppress shear along these three systems. It is to be noted that these three systems are not the major contributor when the loading at $\phi=90^{\circ}$. It is also clear that the loading responses at $\phi=90^{\circ}$ are dictated by softer $\gamma$-phase, while responses $\phi=0^{\circ}$ by harder $r$-phase with LPS. In Ti-rich side, lamellar interface plays major role, while in Al-rich side, phase boundary alone is not playing the dominating role, rather slip systems in the harder phase with long period superstructure adds additional role in the overall anisotropic plastic deformation.

\section{Tension-compression asymmetry prediction}

The model described so far is generalized for the plastic anisotropy and asymmetry. Since the alloy Ti-61.8at.\%Al is highly anisotropic, a high asymmetry in tension and compression can be expected. In the flow rule of the model, asymmetry has been accommodated in the term $|\tau-X|$. Predicted rate dependent asymmetry using the presented model is shown in Fig. 10. Like anisotropy, tensioncompression asymmetry is also highly pronounced for responses at $\phi=90^{\circ}$ orientation. For this case, there is

Table 4 Approximated CRSS values for all slip systems in Ti-61.8at.\%Al alloy. Three harder ordinary systems are marked as bold

\begin{tabular}{llll}
\hline Slip system & CRSS $(\mathrm{MPa})$ & Slip system & CRSS (MPa) \\
\hline $1 .(111)[0-11]$ & 24.5 & $10 .(11-1)[011]$ & 24.5 \\
2.(111)[10-1] & 24.5 & $11 .(11-1)[101]$ & 24.5 \\
$3 .(111)[-110]$ & 14 & $12 .(11-1)[-110]$ & 14 \\
$4 .(-111)[101]$ & 24.5 & $\mathbf{1 3 . ( 0 0 1 ) [ 1 1 0 ]}$ & $\mathbf{2 4 . 5}$ \\
5.(-111)[110] & 14 & $\mathbf{1 4 . ( 0 0 1 ) [ 1 - 1 0 ]}$ & $\mathbf{1 8 . 3}$ \\
6.(-111)[0-11] & 24.5 & $15 .(010)[101]$ & 24.5 \\
7.(1-11)[011] & 24.5 & $16 .(010)[10-1]$ & 24.5 \\
$\mathbf{8 . ( 1 - 1 1 ) [ 1 1 0 ]}$ & $\mathbf{2 3}$ & $17 .(100)[011]$ & 24.5 \\
9.(1-11)[10-1] & 24.5 & $18 .(100)[01-1]$ & 24.5 \\
\hline
\end{tabular}




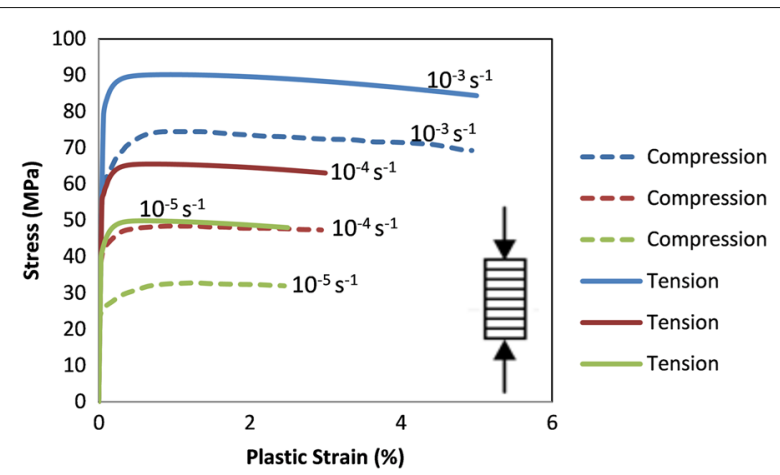

Fig. 10 Predicted tension-compression asymmetry of Ti-61.8at.\%Al at $1050^{\circ} \mathrm{C}$ for different strain rates when lamellar and loading axes are at $90^{\circ}$

no sharp increase or decrease in asymmetry with increasing strain rates i.e. almost similar amount of asymmetry is maintained for all strain rates and for the whole range of deformation. Tensile state is stronger than that of compressive one. At $\phi=90^{\circ}$, it seems the most dominant slip system offers higher resistance in tension influenced mostly by the lamellar morphology. Accuracy of prediction is largely dependent on the accuracy of CRSS both in tension and compression. Since there is no experimental study about the difference of CRSS in tension and compression, the same set of CRSS both for compression and tension has been used, and hence the overall asymmetric results remain as qualitative. While investigating slip activities, the modeling approach shows that the number of contributing slip systems is different in tension and compression, more importantly, the dominating system or major contributing slip systems are different. It is also found that the compressive deformation is dictated by some ordinary slips and tensile deformation is dominated by superdislocation slips. These findings are consistent with Ti-rich lamellar single crystals, for example, Inui et al. (1997) mentioned that the CRSS of some slip systems are dependent on the direction of dislocation motions. However, in Ti-55.5at\% Al single phase single crystal deformed at $700{ }^{\circ} \mathrm{C}$, investigation suggests that the same deformation mode was active in both tension and compression (Zupan and Hemker 2000). This is also quite possible considering simplicity of the single phase microstructure. Further information regarding the tension-compression asymmetry of this alloy can be found in Chowdhury et al. (2017c).

\section{Conclusion}

A short review of Al-rich TiAl alloy family has been presented focusing phases, microstructures, deformation mechanisms, mechanical behavior, etc. A micromechanical modeling approach for the plastic anisotropy along with CRSS estimation technique has also been discussed considering an exemplary alloy from the same family. Analyzing the available literature, the advances and current understanding about this family can be summarized by the following points:

- With the increase of $\mathrm{Al}$-concentration, Al-rich phases $\left(\mathrm{Ti}_{3} \mathrm{Al}_{5}, h-\mathrm{TiAl}_{2}, r-\mathrm{TiAl}_{2}\right.$, etc.) start to grow. Heat treatment parameters, phase stability and the operating temperature etc. direct how many and which phases will exist at the end. Comparing with the Ti-rich side, the formation of one or more stable/metastable long-period superstructures is one of the most characteristic features of the Al-rich alloys, which considerably changes the deformation mechanisms and mechanical properties.

- Controlling hardness and brittleness with the increasing of $\mathrm{Al}$ concentration and annealing temperature is still a challenge for the Al-rich side.

- Due to the presence of different superstructures, some ordinary systems are found to be little harder than other ordinary slips, which is consistent with conventional approaches and observed experimental issues.

- In contrast to Ti-rich side, superlattice dislocation slips are more operative below the peak temperature than that of ordinary slips. In the approximate range of $700-1000{ }^{\circ} \mathrm{C}$, anomalous hardening of different slips is a characteristic feature of the Al-rich alloys. After $1000^{\circ} \mathrm{C}$, a variety of slip systems is expected to be operative depending on the loading orientation.

- At lower temperature, some ordinary dislocations are suppressed to move, however, they can overcome the resistance by changing plane due to high temperature driven thermally active mechanisms like climb, so they become softer. Nevertheless, some ordinary systems might remain hard for certain loading orientations.

- The family of Al-rich alloys are expected to be highly anisotropic and asymmetric. Instead of purely morphological as Ti-rich side, the plastic anisotropy in the Al-rich side is found to be dependent on the lamellar morphology and long period superstructure. So the origins of the anisotropy and the asymmetry for polycrystalline Al-rich alloys are expected to be associated with different length scales e.g. grain scale, lamellar (morphological) scale and superstructural (crystal lattice) scale.

- The slip mechanisms are found to be different in tension and compression.

- Hardening-recovery based phenomenological crystal plasticity model can successfully be used in reproducing the plastic anisotropy of $\mathrm{Al}$-rich $\mathrm{TiAl}$ 
alloys with different superstructures when CRSS are chosen carefully.

\section{Acknowledgements}

We gratefully acknowledge the financial contribution of DFG.

\section{Funding}

This work has been supported by Deutsche Forschungsgemeinschaft (DFG) within the PhD school GRK1554/2.

\section{Availability of data and materials}

Not applicable.

\section{Authors' contributions}

HA planned the possibility, HC completed the relevant literature study and prepared the manuscript. MK, KN and HA supervised the work. All authors read, contributed to the editing of the paper and approved the final manuscript.

\section{Competing interests}

The authors declare that they have no competing interests.

\section{Publisher's Note}

Springer Nature remains neutral with regard to jurisdictional claims in published maps and institutional affiliations.

\section{Author details}

${ }^{1}$ Graduate School for 'Micro-Macro Interactions in Structured Media and Particle Systems', Otto-von-Guericke University, 39106 Magdeburg, Germany. ${ }^{2}$ Institute of Mechanics, Otto-von-Guericke University, 39106 Magdeburg, Germany. ${ }^{3}$ Faculty of Georesources and Materials Engineering, RWTH Aachen, 52056 Aachen, Germany. ${ }^{4}$ Institute of Energy and Climate Research (IEK-2), FZ Jülich, 52425 Jülich, Germany.

Received: 15 May 2017 Accepted: 22 September 2017

Published online: 02 October 2017

\section{References}

Appel F, Paul JDH, Oehring M (2011) Gamma Titanium Aluminide Alloys: Science and Technology. Wiley-VCH Verlag, Weinheim

Appel F, Clemens H, Fischer F (2016) Modeling concepts for intermetallic titanium aluminides. Progress Mater Sci 81:55-124

Asaro R, Needleman A (1985) Overview no. 42 texture development and strain hardening in rate dependent polycrystals. Acta Metallurgica 33(6):923-953

Austin C (1999) Current status of gamma titanium aluminides for aerospace applications. Curr Opinion Solid State Mater Sci 4(3):239-242

Batalu D, Cosmeleata G, Aloman A (2006) Critical analysis of the Ti-Al phase diagrams, Vol. 68, no. 4, pp. 77-90. UPB Scientific Bulletin

Benci J, Ma J, Feist T (1995) Evaluation of the intermetallic compound $\mathrm{Al}_{2} \mathrm{Ti}$ for elevated-temperature applications. Mater Sci Eng A 192:38-44

Braun J, Ellner M (2001) Phase equilibria investigations on the aluminium-rich part of the binary system Ti-Al. Metall Mater Trans A 32(5):1037-1047

Brockman R (2003) Analysis of elastic-plastic deformation in TiAl polycrystals. Int J Plast 19(10):1749-1772

Brown S, Kim K, Anand L (1989) An internal variable constitutive model for hot working of metals. Int J Plast 5(2):95-130

Chakravadhanula V, Kelm K, Kienle L, Duppel V, Lotnyk A, Sturm D, Heilmaier M, Schmitz GJ, Drevermann A, Stein F, Palm M (2011) TEM studies of the ternary $\mathrm{Ti}_{36} \mathrm{Al}_{62} \mathrm{Nb}_{2}$ alloy, Vol. 1295. doi:10.1557/opl.2011.181

Chen G, Peng Y, Zheng G, Qi Z, Wang M, Yu H, Dong C, Liu C (2016) Polysynthetic twinned TiAl single crystals for high-temperature applications. Nat Mater 15:876-881. doi:10.1038/nmat4677

Chowdhury H, Naumenko K, Altenbach H (2016) On the choice of the power law flow rule and its consequences in crystal plasticity. Key Eng Mater 725:359-365

Chowdhury H, Naumenko K, Altenbach H (2017a) Aspects of power law flow rules in crystal plasticity with glide-climb driven hardening and recovery. Intl J Mech Sci. doi:10.1016/j.jimecsci.2017.06.019.

Chowdhury H, Naumenko K, Altenbach H, Krüger M (2017b) Critical stresses estimation by crystal viscoplasticity modeling of rate dependent anisotropy of al-rich tial alloys at high temperature. Archive of Applied Mechanics. doi:10.1007/s00419-017-1291-4. Accepted

Chowdhury H, Naumenko K, Altenbach H, Krüger M (2017c) Rate dependent tension-compression-asymmetry of Ti-61.8at\%Al alloy with long period superstructures at $1050^{\circ} \mathrm{C}$. Mater Sci Eng A 700:503-511

Conti S, Hackl K (2015) Analysis and Computation of Microstructure in Finite Plasticity. Springer International Publishing, Switzerland

Feng Q, Whang S (1999) Cross-slip and glide behavior of ordinary dislocations in single crystal $\gamma$-Ti-56Al. Intermetallics 7(9):971-979

Feng Q, Whang S (2000) Deformation of Ti-56at.\%Al single crystals oriented for single slip by $\frac{1}{2}<110$ ] ordinary dislocations. Acta Materialia 48(17):4307-4321

Fujiwara T, Nakamuraa A, Hosomia M, Nishitania SR, Shiraia Y, Yamaguchia M (1990) Deformation of polysynthetically twinned crystals of TiAl with a nearly stoichiometric composition. Philos Mag A 61(4):591-606

Ghosh S, Anahid M (2013) Homogenized constitutive and fatique nucleation models from crystal plasticity FE simulations of Ti alloys, part 1: Macroscopic anisotropic yield function. Int J Plast 47:182-201

Gregori F, Veyssiere P (1999) Planar debris in plastically deformed al-rich $\gamma$-TiAl. Philos Mag A 79(2):403-421

Gregori F, Veyssiere P (2000) Properties of $\langle 011]\{111\}$ slip in Al-rich $\gamma$-TiAl I. Dissociation, locking and decomposition of $\langle 011$ ] dislocations at room temperature. Philos Mag A 80(12):2913-2932

Gregori F, Veyssiere P (2001) A microstructural analysis of Al-rich $\gamma$-TiA deformed by <011] dislocations. Mater Sci Eng A 309-310:87-91

Gregori F, Penhoud P, Veyssiere P (2001) Extrinsic factors influencing the yield stress anomaly of Al-rich $\gamma$-TiAl. Philos Mag A 81(3):529-542

Grujicic M, Batchu S (2001) A crystal plasticity materials constitutive model for polysynthetically-twinned $\gamma-\mathrm{TiAl}+\alpha_{2}-\mathrm{Ti}_{3} \mathrm{Al}$ single crystals. J Mater Sci 36:2851-2863

Hata S, Higuchi K, Itakura M, Kuwano N, Nakano T, Hayashi K, Umakoshi Y (2002a) Short-range order in al-rich $\gamma$-tial alloys studied by high-resolution transmission electron microscopy with image processing. Philos Mag Lett 82(7):363-372

Hata S, Higuchi K, Itakura M, Kuwano N, Nakano T, Hayashi K, Umakoshi Y (2002b) Short-range order in Al-rich $\gamma$-TiAl alloys studied by high-resolution transmission electron microscopy with image processing. Philos Mag Lett 82(7):363-372

Hata S, Higuchi K, Mitate T, Kuwano N, Itakura M, Tomokiyo Y, Nakano T, Nagasawa Y, Umakoshi Y (2002c) HRTEM observation of partially ordered long-period superstructures in Al-rich TiAl alloys. MRS Proc 753. doi:10.1557/PROC-753-BB4.2

Hata S, Nakano T, Higuchi K, Nagasawa Y, Kuwano N, Itakura M, Tomokiyo Y, Umakoshi Y (2003) Semi-quantitative HRTEM for partially ordered materials: Application to Al-rich TiAl alloys. Mater Sci Forum 426-432:1721-1726

Hata S, Higuchi K, Mitate T, Itakura M, Tomokiyo Y, Kuwano N, Nakano T, Nagasawa Y, Umakoshi Y (2004a) HRTEM image contrast and atomistic microstructures of long-period ordered Al-rich TiAl alloys. J Electron Microsc 53(1):1-9

Hata S, Shiraishi K, Kuwano N, Itakura M, Tomokiyo Y, Nakano T, Umakoshi Y (2004b) TEM Analysis of Long-Period Superstructures in TiAl Single Crystal with Composition Gradient. MRS Proceedings 842. doi:10.1557/PROC-842-S7.5

Hata S, Nakano T, Kuwano N, Itakura M, Matsumura S, Umakoshi Y (2008) Microscopic properties of long-period ordering in Al-rich TiAl alloys. Metall Mater Trans A 39(7):1610-1617

Hautmann D (2013) Titanium Aluminides-A class all by itself. MTU Aero Engines AG 10(1):24-29

Hayashi K, Nakano T, Umakoshi Y (2001) Plastic deformation behaviour and deformation substructure in Al-rich TiAl single crystals deformed at high temperatures. Sci Technol Adv Mater 2:433-441

Hayashi K, Nakano T, Umakoshi Y (2002) Metastable region of $\mathrm{Al}_{5} \mathrm{TI}_{3}$ single-phase in time-temperature-transformation (TTT) diagram of Ti-62.5 at.\% Al single crystal. Intermetallics 10(8):771-781

He Y, Schwarz R, Darling T, Hundley M, Whang S, Wang Z (1997) Elastic constants and thermal expansion of single crystal $\gamma$-TiAl from 300 to $750 \mathrm{~K}$. Mater Sci Eng A 239-240:157-163

Hutchinson W, Barnett M (2010) Effective values of critical resolved shear stress for slip in polycrystalline magnesium and other HCP metals. Scripta Materialia 63(7):737-740 
Inui H, Matsumuro M, Wu D, Yamaguchi M (1997) Temperature dependence of yield stress, deformation mode and deformation structure in single crystals of TiAl (Ti-56 at.\% Al). Philos Mag A 75(2):395-423

Inui H, Chikugo K, Nomura K, Yamaguchi M (2002) Lattice defects and their influence on the deformation behavior of single crystals of TiAl. Mater Sci Eng A 329-331:377-387

Jiao S, Bird N, Hirsch PB, Taylor G (1998) Yield stress anomalies in single crystals of Ti-54.5 at.\% Al: I. Overview and (011) superdislocation slip. Philos Mag A 78(3):777-802

Jiao S, Bird N, Hirsch PB, Taylor G (1999) Yield stress anomalies in single crystals of Ti-54.5 at.\% Al II. 1/2[112](111) slip. Philos Mag A 79(3):609-625

Jiao S, Bird N, Hirsch PB, Taylor G (2001) Yield stress anomalies in single crystals of Ti-54.5 at.\% Al III. Ordinary slip. Philos Mag A 81(1):213-244

Kabirian F, Khan A (2015) Anisotropic yield criteria in $\sigma-\tau$ stress space for materials with yield asymmetry. Int J Solids Struct 67-68:116-126

Kad B, Hazzledine P, Fraser H (1992) Lamellar interfaces and their contribution to plastic flow anisotropy in TiAl-based alloys. MRS Proc 288:495-500

Kad BK, Fraser HL (1994) On the contribution of climb to high-temperature deformation in single phase $\gamma$-TiAl. Philos Mag A 69(4):689-699

Kassner M, Perez-Prado M (2000) Five-power-law creep in single phase metals and alloys. Prog Mater Sci 45(1):1-102

Kawabata T, Kanai T, Izumi O (1985) Positive temperature dependence of the yield stress in TiAl L $1_{0}$ type superlattice intermetallic compound single crystals at 293-1273 K. Acta Metallurgica 33(7):1355-1366

Kawabata T, Kanai T, Izumi O (1994) Dislocation microstructures of a TiAl single crystal with the [110] orientation deformed at 1073 K. Philos Mag A 70(1):43-51

Khadyko M, Dumoulin S, Cailletaud G, Hopperstad O (2016) Latent hardening and plastic anisotropy evolution in AA6060 aluminium alloy. Int J Plast 76:51-74

Khan A, Yu S, Liu H (2012) Deformation induced anisotropic responses of Ti-6Al-4V alloy part II: A strain rate and temperature dependent anisotropic yield criterion. Int J Plast 38:14-26

Koyama T, Doi M, Naito S (2000) Experimental and Theoretical Investigations of the Phase Transformation in Al-rich TiAl Intermetallic Compounds. MRS Proceedings 646. doi:10.1557/PROC-646-N2.2.1

Kuroda M (2014) Plasticity and Beyond: Microstructures, Crystal-Plasticity and Phase Transitions, chap On scale-dependent crystal plasticity models. Springer, Vienna. pp 305-353

Lapin J (2009) TiAl-based alloys: present status and future perspectives. In: Proceedings of 18th International Mettalurgical and Materials Conference. Conference Metal 2009, Ostrava, Czech Republic

Lebensohn R, Uhlenhut H, Hartig C, Mecking H (1998) Plastic flow of $\gamma$-TiAl-based polysynthetically twinned crystals: micromechanical modeling and experimental validation. Acta Materialia 46(13):4701-4709

Lei C, Xu Q, Sun YQ (2000) TEM investigation of interfaces between $\mathrm{Ti}_{3} \mathrm{Al}_{5}$ and $\mathrm{TiAl}_{2}$. Physica Status Solidi (a) 179(1):77-82

Lei C, Xu Q, Sun Y (2001) Phase orientation relationships in the TiAl-TiAl 2 region. Mater Sci Eng A 313:227-236

Leng Z, Pan H, Guo C, Wang Z, Zou G, Jiang F (2016) Asymmetry of tensile-compressive mechanical behaviors of $\mathrm{Mg}$-RE-Zn alloy strengthened by long period stacking ordered phase. Mater Sci Eng A 667:468-472

Li H, Hu X, Yang H, Li L (2016) Anisotropic and asymmetrical yielding and its distorted evolution: Modeling and applications. Int J Plast 82:127-158

Li J, Weng G (1998) Time-dependent creep of a dual-phase viscoplastic material with lamellar structure. Int J Plast 14(8):755-770

Liu K, Dong X, Xie H, Wu Y, Peng F, Chen F (2016) Asymmetry in the hot deformation behavior of AZ31B magnesium sheets. Mater Sci Eng A 659:198-206

Marketz W, Fischer F, Clemens H (2003) Deformation mechanisms in TiA intermetallics-experiments and modeling. Int J Plast 19(3):281-321

Mathur K, Dawson P (1989) On modeling the development of crystallographic texture in bulk forming processes. Int J Plast 5(1):67-94

Meric L, Poubanne P, Cailletaud G (1991) Single crystal modeling for structural calculations: Part 1 - Model presentation. ASME J Eng Mater Technol 113(1):162-170

Nakano T, Matsumoto K, Seno T, Oma K, Umakoshi Y (1996) Effect of chemical ordering on the deformation mode of Al-rich Ti-Al single crystals. Philos Mag A 74(1):251-268

Nakano T, Hayashi K, Ashida K, Umakoshi Y (1998) Effect of $\mathrm{Al}_{2}$ Ti Phase on Plastic Behavior in Ti-62.5at.\%Al Single Crystals. In: Symposium: High-Temperature Ordered Intermetallic Alloys VIII. Cambridge University Press, UK Vol. 552. doi:10.1557/PROC-552-KK5.9.1
Nakano T, Negishi A, Hayashi K, Umakoshi Y (1999) Ordering process of $\mathrm{Al}_{5} \mathrm{Tl}_{3}$, $h$ - $\mathrm{Al}_{2} \mathrm{Ti}$ and $r$-Al $\mathrm{I}_{2} \mathrm{Ti}$ with $\mathrm{FCC}$-based long-period superstructures in rapidly solidified Al-rich TiAl alloys. Acta Materialia 47(4):1091-1104

Nakano T, Hayashi K, Nagasawa Y, Umakoshi Y (2002a) Plastic Deformation Behavior of $\mathrm{Al}_{5} \mathrm{Tl}_{3}$ Single-Phase Single Crystals. MRS Proceedings 753. doi:10.1557/PROC-753-BB5.8

Nakano T, Hayashi K, Umakoshi Y (2002b) Formation and stability of transitional long-period superstructures in Al-rich TiAl single crystals. Philos Mag A 82:763-777

Nakano T, Hayashi K, Umakoshi Y, Chiu Y, Veyssiere P (2004) Effects of long-period superstructures on plastic properties in Al-rich TiAl single crystals. MRS Proceedings 842. doi:10.1557/PROC-842-S7.4

Nakano T, Hayashi K, Umakoshi Y, Chiu Y, Veyssiere P (2005) Effects of Al concentration and resulting long-period superstructures on the plastic properties at room temperature of Al-rich TiAl single crystals. Philos Mag 85(22):2527-2548

Nakano T, Hata S, Hayashi K, Umakoshi Y (2012) Some Long-Period Superstructures and the Related Motion of Dislocations in Al-Rich TiAl Single Crystals. In: Supplemental Proceedings: Materials Properties, Characterization, and Modeling. Wiley, New Jersey Vol. 2. pp 797-804

Naumenko K, Altenbach H (2016) Modeling High Temperature Materials Behavior for Structural Analysis: Part I: Continuum Mechanics Foundations and Constitutive Models, vol 28. Springer International Publishing, Switzerland

Ohno N, Wang JD (1993) Kinematic hardening rules with critical state of dynamic recovery, part l: formulation and basic features for ratchetting behavior. Int J Plast 9(3):375-390

Palm M, Zhang L, Stein F, Sauthoff G (2002) Phases and phase equilibria in the Al-rich part of the Al-Ti system above $900{ }^{\circ} \mathrm{C}$. Intermetallics 10(6):523-540

Palm M, Engberding N, Stein F, Kelm K, Irsen S (2012) Phases and evolution of microstructures in Ti-60at.\%Al. Acta Materialia 60:3559-3569

Roters F, Eisenlohr P, Hantcherli L, Tjahjanto D, Bieler T, Raabe D (2010) Overview of constitutive laws, kinematics, homogenization and multiscale methods in crystal plasticity finite-element modeling: Theory, experiments, applications. Acta Materialia 58(4):1152-1211

Salehinia I, Bahr D (2014) Crystal orientation effect on dislocation nucleation and multiplication in FCC single crystal under uniaxial loading. Int J Plast 52:133-146

Schnabel J, Bargmann S (2017) Accessing colony boundary strengthening of fully lamellar TiAl alloys via micromechanical modeling. Materials 10(8):896

Stein F, Zhang L, Sauthoff G, Palm M (2001) TEM and DTA study on the stability of $\mathrm{Al}_{5} \mathrm{Ti}_{3}$ - and $\mathrm{h}-\mathrm{Al}_{2} \mathrm{Ti}$-superstructures in aluminium-rich TiAl alloys. Acta Materialia 49(15):2919-2932

Stewart J, Cazacu O (2011) Analytical yield criterion for an anisotropic material containing spherical voids and exhibiting tension-compression asymmetry. In J Solids Struct 48(2):357-373

Sturm D (2010) Herstellung und eigenschaften Al-reicher TiAl legierungen. PhD thesis, OvGU Magdeburg

Sturm D, Heilmaier M, Saage H, Paninski M, Schmitz G, Drevermann A, Palm M, Stein F, Engberding N, Kelm K, Irsen S (2009) Creep strength of centrifugally cast Al-rich TiAl alloys. Mater Sci Eng A 510-511:373-376

Sturm D, Heilmaier M, Saage H, Aguilar J, Schmitz G, Drevermann A, Palm M, Stein F, Engberding N, Kelm K, Irsen S (2010) Creep strength of a binary $\mathrm{Al}_{62} \mathrm{Ti}_{38}$ alloy. Int J Mater Res 101(5):676-679

Tanaka K (1996) Single-crystal elastic constants of gamma-TiAl. Philos Mag Letters 73(2):71-78

Tang P, Tang B, Su X (2011) First-principles studies of typical long-period superstructures $\mathrm{Al}_{5} \mathrm{Ti}_{3}, \mathrm{~h}-\mathrm{Al}_{2} \mathrm{Ti}$ and $\mathrm{r}-\mathrm{Al}_{2} \mathrm{Ti}$ in $\mathrm{Al}$-rich TiAl alloys. Comput Mater Sci 50(4):1467-1476

Tuninetti V, Gilles G, Milis O, Pardoen T, Habraken A (2015) Anisotropy and tension compression asymmetry modeling of the room temperature plastic response of Ti-6Al-4V. Int J Plast 67:53-68

Umakoshi Y, Nakano T, Ashida K (1999) High-temperature deformation in Ti-62.5at.\%Al single crystals containing small $\mathrm{Al}_{2}$ Ti-type precipitates. Mater Sci Forum 304-306:163-168

Viguier B, Hemker K, Bonneville J, Louchet F, Martin J (1995) Modelling the flow stress anomaly in $\gamma$-TiAl i. experimental observations of dislocation mechanisms. Philos Mag A 71(6):1295-1312

Vinogradov A, Orlov D, Danyuk A, Estrin Y (2015) Deformation mechanisms underlying tension-compression asymmetry in magnesium alloy ZK60 revealed by acoustic emission monitoring. Mater Sci Eng A 621:243-251 
Wegmann G, Suda T, Maruyama K (2000) Deformation characteristics of polysynthetically twinned (PST) crystals during creep at $1150 \mathrm{~K}$. Intermetallics 8(2):165-177

Werwer M, Cornec A (2006) The role of superdislocations for modeling plastic deformation of lamellar TiAl. Int J Plast 22(9):1683-1698

Xu S, Xu X, Xu Y, Liang Y, Lin J (2016) Phase transformations and phase equilibria of a Ti-46.5Al-16.5 Nb alloy. Mater Des 101:88-94

Yoo M, Fu C (1998) Physical constants, deformation twinning, and microcracking of titanium aluminides. Metall Mater Trans A 29:49- 63

Yoon J, Lou Y, Yoon J, Glazoff M (2014) Asymmetric yield function based on the stress invariants for pressure sensitive metals. Int J Plast 56:184-202

Zambaldi C (2010) Micromechanical modeling of $\gamma$-TiAl based alloys. PhD thesis, RWTH Aachen

Zambaldi C, Raabe D (2010) Plastic anisotropy of $\gamma$-TiAl revealed by axisymmetric indentation. Acta Materialia 58(9):3516-3530

Zambaldi C, Roters F, Raabe D (2011) Analysis of the plastic anisotropy and pre-yielding of $\left(\gamma / \alpha_{2}\right)$-phase titanium aluminide microstructures by crystal plasticity simulation. Intermetallics 19(6):820-827

Zhang L, Palm M, Stein F, Sauthoff G (2001) Formation of lamellar microstructures Al-rich TiAl alloys between 900 to $1100^{\circ} \mathrm{C}$. Intermetallics 9:229-238

Zhang M, Zhang J, McDowell D (2007) Microstructure-based crystal plasticity modeling of cyclic deformation of Ti-6Al-4V. Int J Plast 23(8):1328-1348

Zupan M, Hemker K (2000) Measurement of the tension/compression asymmetry exhibited by single crystalline $\gamma$-Ti-55.5at\%Al. MRS Proceedings 646

Zupan M, Hemker K (2003) Yielding behavior of aluminum-rich single crystalline $\gamma$-TiAl. Acta Materialia 51(20):6277-6290

\section{Submit your manuscript to a SpringerOpen ${ }^{\circ}$ journal and benefit from:}

- Convenient online submission

- Rigorous peer review

- Open access: articles freely available online

- High visibility within the field

- Retaining the copyright to your article

Submit your next manuscript at $\gg$ springeropen.com 